\title{
Roadmap to New Virulence Determinants in Pseudomonas syringae: Insights from Comparative Genomics and Genome Organization
}

\author{
Magdalen Lindeberg, ${ }^{1}$ Christopher R. Myers, ${ }^{2}$ Alan Collmer, ${ }^{1}$ and David J. Schneider ${ }^{1,3}$ \\ ${ }^{1}$ Department of Plant Pathology, Cornell University, Ithaca, NY 14853, U.S.A.; ${ }^{2}$ Computational Biology Service Unit, \\ Center for Advanced Computing, Cornell University, Ithaca, NY 14853, U.S.A.; ${ }^{3}$ U. S. Department of Agriculture \\ Agricultural Research Service, Ithaca, NY 14853, U.S.A.
}

Submitted 9 November 2007. Accepted 31 January 2008.

Systematic comparison of the current repertoire of virulence-associated genes for three Pseudomonas syringae strains with complete genome sequences, $P$. syringae pv. tomato DC3000, $P$. syringae pv. phaseolicola $1448 A$, and $P$. syringae pv. syringae $\mathrm{B} 728 \mathrm{a}$, is prompted by recent advances in virulence factor identification in $P$. syringae and other bacteria. Among these are genes linked to epiphytic fitness, plant- and insect-active toxins, secretion pathways, and virulence regulators, all reflected in the recently updated DC3000 genome annotation. Distribution of virulence genes in relation to $P$. syringae genome organization was analyzed to distinguish patterns of conservation among genomes and association between genes and mobile genetic elements. Variable regions were identified on the basis of deviation in sequence composition and gaps in syntenic alignment among the three genomes. Mapping gene location relative to the genome structure revealed strong segregation of the HrpL regulon with variable genome regions (VR), divergent distribution patterns for toxin genes depending on association with plant or insect pathogenesis, and patterns of distribution for other virulence genes that highlight potential sources of strain-to-strain differences in host interaction. Distribution of VR among other sequenced bacterial genomes was analyzed and future plans for characterization of this potential reservoir of virulence genes are discussed.

Additional keywords: Arabidopsis, nonribosomal peptide synthase, pathogenicity island, REP sequence.

The genus Pseudomonas occupies a wide range of environments, with many strains and species adapted to niches associated with animals, plants, and insects. To date, genome sequences have been completed for 13 pseudomonads, with three sequences derived from isolates of Pseudomonas syringae, a species characterized by its ability to epiphytically colo-

Corresponding author: D. J. Schneider; Dave.Schneider@ars.usda.gov

* The $\boldsymbol{e}$-Xtra logo stands for "electronic extra" and indicates one supplementary figure and three supplemental tables are published online.

This article is in the public domain and not copyrightable. It may be freely reprinted with customary crediting of the source. The American Phytopathological Society, 2008. nize and cause disease in plants. Many of the individual $P$. syringae pathovars, named for the plant species from which they were isolated, share a generalized disease cycle characterized by dissemination in association with plant material, colonization of the plant surface, and onset of disease upon entry into the plant apoplast. However, dimensions of the bacterial-host interaction, including epiphytic fitness, host range, characteristic symptoms, and disease severity, vary substantially among pathovars and strains.

The three sequenced $P$. syringae strains represent each of the major monophyletic groups within the species (Sarkar and Guttman 2004; Sawada et al. 2002) and differ in the nature of their interaction with host plants (Buell et al. 2003; Feil et al. 2005; Joardar et al. 2005a). P. syringae pv. tomato DC3000 is a causal agent of bacterial speck on tomato and Arabidopsis. Effector proteins secreted by the type III secretion system (T3SS) have been extensively characterized in this strain, and it has emerged as an important model system for exploring interactions between bacterial and plant gene products during the infection process (Lindeberg et al. 2006; Nomura et al. 2005). P. syringae pv. phaseolicola $1448 \mathrm{~A}$ is an economically important pathogen of bean and is closely related to strains causing devastating outbreaks in Africa (Fourie 1998). Type III effectors and other members of the HrpL regulon have also been extensively characterized in this strain (Chang et al. 2005; Vencato et al. 2006). P. syringae pv. syringae B728a is the causal agent of brown spot of bean and, of the three sequenced strains, is best adapted for epiphytic survival and growth on the plant surface (Hirano and Upper 2000; Marco et al. 2005; Monier and Lindow 2003). Though many gene products have been implicated in different stages of host interaction, including T3SS effector proteins, toxins, siderophores, adhesins, and proteins contributing to stress tolerance, knowledge of the full range of factors contributing to host association remains incomplete. What is our present understanding of gene products implicated in adaptation to the plant-associated niche? Of the factors thus far identified, which ones underlie strategies shared by diverse pathovars and which ones confer pathovar-specific phenotypes? These questions can be addressed by comparison of the repertoire of virulence and host-association genes among the three strains, followed by analysis of their locations relative to overall genome structure. Though the ultimate goal of assessing patterns in gene distribution is the identification of regions likely enriched for additional host-association genes, the pathovar-specific and species-specific genes 
and regions identified during these analyses represent a valuable pool of potential molecular markers for use in genome-based diagnostics of $P$. syringae isolates.

To date, a systematic three-way comparison has not been conducted for the $P$. syringae pv. tomato DC3000, P. syringae pv. phaseolicola 1448A, and $P$. syringae pv. syringae $\mathrm{B} 728 \mathrm{a}$ genomes. "Lineage-specific regions" in DC3000 relative to $P$. putida and $P$. aeruginosa were previously identified based on enrichment for mobile genetic elements and DC3000-specific genes (Joardar et al. 2005b), but differences in gene repertoire and organization among $P$. syringae pathovars have not been thoroughly investigated.

Review of the repertoire of genes implicated in virulence and host association of $P$. syringe is timely, given the significant advances in identification and confirmation of predicted virulence factors since publication of the original genome annotations (Buell et al. 2003; Feil et al. 2005; Joardar et al. 2005a). Some of this work has been conducted in $P$. syringae, while other insights are derived from ongoing research in other bacterial pathogens that has greatly expanded the pool of characterized host-association factors with which the $P$. syringae genomes can be screened. Gene products with confirmed and candidate roles in virulence and host association are described in the following sections, with particular emphasis on those more recently characterized. These new findings are being incorporated into the appropriate genome annotation records at National Center for Biotechnology Information (NCBI) with updates summarized on the Pseudomonas-Plant Interaction website.

\section{Recent advances in characterization} of $\boldsymbol{P}$. syringae virulence and host-association factors.

Epiphytic fitness determinants-biofilms, osmoprotection, and iron uptake. Survival on the leaf surface prior to or exclusive of subsequent infection requires the ability to withstand stresses specific to the epiphytic environment and acquire nutrients in this highly circumscribed environment (Hirano and Upper 2000). Production of type IV pili and the exopolysaccharide alginate, phenotypes associated with attachment and biofilm-associated protection in numerous genera, have been previously shown to contribute to either epiphytic fitness, virulence, or both in P. syringae (Chang et al. 2007; Roine et al. 1998; Yu et al. 1999). However, neither alginate nor the polysaccharide levan appear to be required for biofilm formation in vitro, suggesting that as-yet-uncharacterized polysaccharides are critical to $P$. syringae biofilm formation (Laue et al. 2006). A recently identified candidate is the mannose-rich Psl (polysaccharide synthesis locus) exopolysaccharide, shown by $\mathrm{Ma}$ and associates (2006) to play a critical role in adhesion initiation and biofilm maintenance by $P$. aeruginosa. Given that orthologs of all 11 loci essential for Psl biosynthesis are present in $P$. syringae (PSPTO_3529 to 3539), this polysaccharide may play a significant role in $P$. syringae-host interactions. A second polysaccharide with potential involvement in $P$. syringae biofilm formation is acetylated cellulose, implicated in biofilm formation and epiphytic fitness in $P$. fluorescens SBW25 (Gal et al. 2003; Spiers et al. 2003). The complete wss biosynthetic cluster, characterized in SBW25, is present in $P$. syringae pv. tomato DC3000 (PSPTO_1026 to 1034) and production of cellulose by DC3000 has been confirmed (Ude et al. 2006).

Bacteria living epiphytically experience significant oxidative and osmotic stress (Hirano and Upper 2000). Tolerance of UV and oxidative stress is typically addressed through deployment of enzymes involved in quenching of reactive oxygen species as well as rulAB-encoded DNA polymerase for repair of UV damage (Sundin and Murillo 1999). Osmotic stress is mitigated by exopolysaccharide production and import of osmoprotective compounds that, like betaine, function directly as compatible solutes or, like choline, serve as precursors for compatible solute synthesis (Boncompagni et al. 1999; Landfald and Strom 1986; Wood 1999). Recent investigation of osmoprotection mechanisms in P. syringae pv. tomato DC3000 has led to identification of two transporters shown to be capable of in vitro uptake of osmoprotective compounds: i) the OpuC $\mathrm{ABC}$ transporter (PSPTO_4575 to 4578), implicated in the uptake of betaine and choline (Chen and Beattie 2007) and ii) the BCCT family transporter, BetT (PSPTO_5269), involved in choline transport (Chen and Beattie 2008). Interestingly, uptake of exogenous choline confers greater osmoprotection in DC3000 than betaine, the typical substrate observed for other bacteria (Miller and Wood 1996). Conversion of choline to betaine is likely accomplished by gene products encoded by the betIBA locus (PSPTO_0440 to 0441, 0443), similar to those characterized in Escherichia coli (Lamark et al. 1991).

Acquisition of nutrients is similarly essential for survival on the leaf surface, with uptake of limited iron accomplished by deployment of iron-chelating siderophores. The most definitive evidence supporting the role of siderophores in epiphytic growth comes from studies showing a growth defect for siderophore-deficient $P$. syringae pv. syringae $\mathrm{B} 728 \mathrm{a}$ in the presence of plant-derived iron-chelated compounds (Karamanoli and Lindow 2006). In planta expression of the siderophore pyoverdin has been recently confirmed in $P$. syringae pv. tomato DC3000 grown in iron-limiting conditions (Jones et al. 2007), and a fitness benefit was observed when expressed under ironlimiting conditions (M. W. Wildermuth, personal communication). In contrast, the siderophore yersiniabactin, though clearly expressed, does not appear to contribute positively to fitness of B728a under iron-limiting conditions (Jones et al. 2007).

The three $P$. syringae genome sequences also contain numerous genes annotated as TonB-dependent receptors (TBDR). Though generally implicated in uptake of siderophores, recent research in Xanthomonas campestris has revealed that TBDR-mediated uptake of carbohydrates is required for full virulence on Arabidopsis, suggesting that selected TBDR orthologs in $P$. syringae may also play determining roles in the uptake of critical, nonferric substrates (Blanvillain et al. 2007).

T3SS effector proteins, helpers, and other members of the HrpL regulon. Following passage from the epiphytic surface through stomatal openings, bacteria must actively defeat plant defense responses in order to progress to the disease state. As agents deployed to suppress both basal and gene-for-gene resistance following bacterial entry into the plant, Hop effector proteins represent a critically important class of virulence factors (Nomura et al. 2005). Characterized on the basis of their regulation by the HrpL alternate sigma factor and translocation by the T3SS, 46 families of Hop effectors and seven families of so-called "helper" proteins involved in facilitating transit of the effector proteins through the T3SS have been identified in the sequenced $P$. syringae strains (Chang et al. 2005; Ferreira et al. 2006; Fouts et al. 2002; Greenberg and Vinatzer 2003; Guttman et al. 2002; Petnicki-Ocwieja et al. 2002; Vencato et al. 2006) and have been reviewed previously (Lindeberg et al. 2006). HrpL-dependent expression of selected non-hop genes has also been experimentally confirmed in P. syringae pv. tomato DC3000 and P. syringae pv. phaseolicola 1448A (Ferreira et al. 2006; Vencato et al. 2006). Ongoing studies have revealed a wide variety of in planta target sites and specific activities for individual effectors including AvrPto1 (Lin and Martin 2007; Xing et al. 2007), AvrPtoB (Abramovitch and Martin 2005; Rosebrock et al. 2007), AvrE1 (Badel et al. 2006), HopF2 (Robert-Seilaniantz et al. 2006), HopI1 (Jelenska et al. 2007), HopU1 (Fu et al. 2007), HopM1 (Badel et al. 2006), 
HopN1 (Lopez-Solanilla et al. 2004), HopQ1-1 (RobertSeilaniantz et al. 2006; Wei et al. 2007), and HopAO1 (Bretz et al. 2003; Espinosa et al. 2003).

Recent investigations also shed light on the respective contributions of T3SS helper proteins to the translocation process. Kvitko and associates (2007) report that HopAK1 and HopP1 share essential harpin-like properties with the previously identified HrpZ and HrpW and that HrpW, HrpZ, and HopAK1 play essential roles in translocation of effector proteins into the plant cell. These three proteins also appear to have an overlapping function with the predicted translocator, HrpK (Kvitko et al. 2007; Petnicki-Ocwieja et al. 2005). The class of helper proteins with lytic transglycosylase activity, facilitating passage of the Type III pilus component through the bacterial peptidoglycan layer, includes $\mathrm{HrpH}$ and HopAJ1 and the harpin-like HopP1. HrpH appears to be the primary specialized lytic transglycosylase in $P$. syringae, with HopAJ1 and HopP1 having secondary, overlapping functions (Oh et al. 2007).

Noneffector members of the HrpL regulon linked to a role in either fitness, virulence, or both include an ApbE ortholog (PSPTO_2105) implicated in the alternative pyrimidine biosynthetic pathway in Salmonella typhimurium (Beck and Downs 1998) and an alcohol dehydrogenase (PSPTO_0834). Both loci have been shown to impact bacterial growth in Arabidopsis (Vencato et al. 2006). Though separated from an upstream HrpL binding site by an intervening insertion sequence, a potential role for the DC3000 gene cluster PSPTO_0873 to 0875 is suggested by the finding that the orthologous $h s v$ operon in Erwinia amylovora contributes to virulence on apple shoots (Oh et al. 2005).

Toxins and other T3SS-independent virulence factors. $P$. syringae strains typically produce phytotoxins using nonribosomal peptide synthases and polyketide synthases, which contribute significantly to virulence in the pathovars in which they occur (Bender et al. 1999; Donadio et al. 2007; Raaijmakers et al. 2006). Previously characterized toxins include lipodepsipeptidic toxins such as syringomycin and syringopeptin, involved in both attachment and surfactant activity (Raaijmakers et al. 2006), and antimetabolite toxins such as phaseolotoxin and tabtoxin, which target specific metabolic pathways in the host. $P$. syringae pv. tomato DC3000 produces coronatine, an adduct of the polyketide coronafacic acid and an isoleucine derivative, coronamic acid. In addition to roles in suppression of salicylic acid-mediated defense (Kloek et al. 2001) and activation of the jasmonic acid (JA)-signaling pathway through mimicry of JA (Zhao et al. 2003), recent research has revealed a critical role for coronatine in suppression of stomatal defense (Melotto et al. 2006; Underwood et al. 2007).

Biosynthetic loci for two additional $P$. syringae toxins have recently been identified. The first of these, characterized in DC3000, consists of syfRABCD (PSPTO_2828 to 2832), which encodes gene products responsible for production of six related lipodepsipeptidic compounds termed "syringofactins" SyrA to SyrF (Berti et al. 2007). Though linear in structure, the syringofactins exhibit properties similar to previously characterized cyclic lipodepsipeptidic toxins and are required for both surfactant activity and swarming motility (Berti et al. 2007).

The second new toxin is the ornithine $N$-acetyltransferase inhibitor "mangotoxin," identified in P. syringae pv. syringae UMAF0158A as a virulence factor in apical necrosis of mango (Arrebola et al. 2003). Gene clusters orthologous to the $P$. syringae pv. syringae UMAF0158A mangotoxin biosynthetic genes are found in other $P$. syringae genomes (e.g., PSPTO_5452 to 5458 in DC3000). A potentially widespread role in virulence is predicted by the observation that UMAF0158A impaired in mangotoxin production is reduced in virulence on tomato (Arrebola et al. 2007).
Screening the $P$. syringae genomes for genes orthologous to virulence determinants in diverse bacterial pathogens has revealed a growing list of candidate toxins and other gene products with surprising similarity to virulence determinants deployed by bacterial pathogens of insects. For example, the two most significant virulence factors thus far characterized in Pseudomonas entomophila L48, a recently identified and sequenced pathogen of genus Drosophila, are a nonribosomal peptide synthase and the metalloprotease AprA. Encoded by PSEEN_0132, the nonribosomal peptide synthase and flanking loci are highly orthologous to none other than the biosynthetic cluster responsible for mangotoxin production (I. Vallet-Gely, personal communication). The metalloprotease AprA, abundantly secreted and required for $P$. entomophila survival and pathogenicity in host Drosophila (Liehl et al. 2006), also has a closely related ortholog in $P$. syringae (PSPTO_3332) (Vodovar et al. 2006).

Other genes present in the $P$. syringae genomes share similarity with insect active toxins deployed by nematode symbionts Xenophabdus nematophila and Photorhabdus luminescens. The binary toxin $x a x A B$, encoded by $X$. nematophila, was initially reported to have a single orthologous locus in $P$. syringae pv. syringae B728a (Vigneux et al. 2007), but paralogous loci are actually present at two locations in all three $P$. syringae genomes (PSPTO_4570 to 4571 and PSPTO_5625 and 4287 in DC3000). Orthologs of toxin complex (Tc) genes, first characterized in Photorhabdus luminescens and encoding high molecular weight proteins with insecticidal activity (Pinheiro and Ellar 2007; Waterfield et al. 2001), are also found at diverse locations in the $P$. syringae genomes, with the cluster corresponding to $P$. syringae pv. tomato DC3000 loci PSPTO_4341 to 4344 encoding representatives of each of the three major families of Tc proteins (TcdA, TcdB, TccC).

Though experimental evidence is less definitive, chitinases, hemolysins, and lipases have also been implicated in bacterial pathogenesis of insects (Vodovar et al. 2006). Predicted members of these gene families are found in one or more of the $P$. syringae genomes.

Secretion pathways. All three $P$. syringae genomes possess a well-characterized T3SS, annotated orthologs of the Type II secretion components, and numerous Type I ABC transporters. Additional cryptic copies of the type II and III pathways are found in P. syringae pv. phaseolicola 1448A. A more recently identified $P$. syringae secretion pathway is the twin-arginine transport (Tat) pathway, experimentally characterized in $P$. syringae pv. tomato DC3000 (PSPTO_5155 to 5157) and involved in translocation of folded-proteins protein complexes across the cytoplasmic membrane prior to type II-dependent passage across the outer membrane (Maillard et al. 2007). Disruption of the Tat pathway in DC3000 results in a reduction in virulence on Arabidopsis, with two lipases, PlcA1 (PSPTO_3648) and PlcA2 (PSPTO_B0005), shown to employ the pathway for extracellular localization (Bronstein et al. 2005).

Genes encoding components of the newly described type VI secretion system (T6SS) are also present at two locations in $P$. syringae pv. tomato DC3000. Mutations in the T6SS significantly reduce virulence in several bacterial pathogens, including Vibrio cholerae, P. aeruginosa, and Burkholderia pseudomallei (Mougous et al. 2006; Pukatzki et al. 2006; Schell et al. 2007). Recent work suggests that elements of the secretion apparatus itself assemble into a structure that punctures cells in a manner analogous to phage tail spikes, but the substrates delivered through this structure are as yet uncharacterized (Pukatzki et al. 2007).

Regulation of virulence-related genes. Recognition of environmental variables and coordinated control of the gene products required for successful exploitation of and transition be- 
tween the epiphytic and apoplastic niches is accomplished by a complex network of regulatory controls, recently reviewed by Mole and associates (2007) for diverse phytopathogenic bacteria. Among these controls are an array of alternate sigma factors and quorum-sensing signals, the latter being linked to regulation of traits associated with epiphytic fitness and virulence in P. syringae pv. syringae B728a (Quinones et al. 2005). Research on factors controlling expression of the acyl homoserine lactone signal (AHL) integral to quorum sensing has led to identification of two new regulators, AefR and PsrA. The first of these upregulates AHL synthesis in P. syringae pv. tomato DC3000 and P. syringae pv. syringae B728a, while PsrA downregulates AHL synthesis through its effect on both AefR and RpoS (Chatterjee et al. 2007; Quinones et al. 2004). The recently characterized LadS activator and RetS repressor (Ventre et al. 2006), integral to switching $P$. aeruginosa from its freeliving motile state to multicell biofilm via control of small RNA transcription, have not been studied in $P$. syringae, but orthologs of retS and rsmA encoding a small RNA binding protein are present, suggesting that a related network may contribute to regulation of fitness and virulence determinants in $P$. syringae.

As previously mentioned, the T3SS and substrates belong to a group of genes regulated by the alternative sigma factor HrpL, expression of which is, in turn, regulated by NtrC-like transcription activators $\mathrm{HrpR}$ and $\mathrm{HrpS}$ (Chatterjee et al. 2002). Genes regulated by HrpL have been comprehensively characterized in $P$. syringae pv. tomato DC3000 (Fereirra et al. 2006; Fouts et al. 2002) and P. syringae pv. phaseolicola 1448A (Chang et al. 2005; Vencato et al. 2006) and those regulated by HrpRS in DC3000 (Lan et al. 2006). HrpL binding sites have since been incorporated into the $P$. syringae genome annotations and represent a valuable addition to information stored in those records.

In view of the expanding repertoire of gene products implicated in bacterial-host interaction, the following questions arise. Which among these gene products are limited to specific lineages, indicative of a role in pathovar or strain-specific adaptations, and which are more widely distributed, suggesting involvement in more universal functions shared by multiple pathovars in diverse plant hosts? Are the widely distributed factors found in syntenically conserved regions consistent with ancient association with the lineage, or are they found in regions exhibiting a high degree of genetic exchange, indicative of recent acquisition or rearrangement? For genes subject to high rates of duplication and horizontal transfer, is there evidence of persistent linkages between virulence genes or with mobile genetic elements that could reveal functional associations or underlying mechanisms of transfer?

\section{Mapping core and variable genome regions (VR) in the $P$. syringae genomes.}

Bacterial genomes are composed of mosaics of relatively stable core regions interspersed with regions exhibiting either high levels of variation in content, alignment, or both relative to related genomes (Hacker and Kaper 2000; Welch et al. 2002). Sometimes described as genomic islands or pathogenicity islands (when components are implicated in virulencerelated functions), these regions are shaped by a range of processes including excision, recombination, duplication, and horizontal transfer (Gal-Mor and Finlay 2006). In addition to alterations in alignment or gene synteny relative to related genomes, VR are often characterized by deviations in the composition of the DNA sequence and typically are associated with features such as mobile genetic elements, tRNAs, and intergene repetitive elements (REP sequences) (Karlin 2001; Lawrence and Ochman 1997; Paulsen et al. 2003; Tobes and Pareja 2005).
Though VR are frequently identified on the basis of enrichment for genes unique to a particular genome or group of closely related genomes, the approach described here focuses on gaps in the genome alignment (syntenic divergence) to maximize identification of unique genes in addition to those present in multiple genomes but acquired by horizontal transfer or subject to intragenomic rearrangement. Sites of syntenic divergence were identified by generating pairwise comparisons of DC3000, 1448A, and B728a using BLASTN (Altschul et al. 1990) and MSPcrunch (Sonnhammer and Durbin 1994) and by analysis of the resulting output with the Artemis Comparison Tool (Carver et al. 2005).

Compositional deviation in the DNA sequence was also measured not only to evaluate the likelihood of horizontal acquisition of syntenically disrupted regions but also to reveal regions of more ancient horizontal transfer in which syntenic disruption may not be present. Deviation in sequence composition is frequently quantitated using sequence properties such as variation in GC content and skews in the dinucleotide or trinucleotide composition (Hsiao et al. 2005; Paulsen et al. 2003); however, the fixed-order methods typically used do not maximally capture local composition. The Alien_hunter application compensates by simultaneously assessing compositional deviation at multiple levels, using variable order compositional distribution, with a two-state second-order hidden Markov model applied to optimize boundary prediction (Vernikos and Parkhill 2006). Previously shown to identify novel pathogenicity islands in Salmonella enterica serovar Typhi CT18 (Vernikos and Parkhill 2006), Alien_hunter was used to analyze the genomes of the three fully sequenced $P$. syringae pathovars, using the default threshold for compositional deviation.

Synthesizing data derived from the two approaches, VR were defined as those exhibiting either gaps in genome alignment $\geq 5 \mathrm{~kb}$ in at least one pairwise comparison or, in the absence of syntenic divergence, deviation in sequence composition predicted by Alien_hunter at corresponding locations in all three strains. Boundaries of syntenically divergent regions were established based on the locations of flanking regions exhibiting $>5-\mathrm{kb}$ alignment for all three genomes. For VR identified by both syntenic disruption and compositional deviation, the final region size was determined according to the larger of the two predictions. For the purpose of this analysis, the plasmids of $P$. syringae pv. tomato DC3000 and P. syringae pv. phaseolicola 1448A are each considered discrete VR.

As previously described, the $P$. syringae genomes contain several major genome rearrangements relative to one another, with regions as large as $500 \mathrm{~kb}$ inverted and rearranged relative to the rest of the genome (Feil et al. 2005; Joardar et al. 2005a). Given that boundaries for individual VR are defined relative to the DNA immediately flanking, placement in relation to the major rearrangements was not an issue for most of the VR identified. However, for those VR located at the boundaries of these rearrangements, region size was determined according to the distance between flanking blocks of aligned DNA, even when the respective flanks were not aligned relative to each other.

Application of these guidelines resulted in the prediction of 107, 87, and 78 VR for $P$. syringae pv. tomato DC3000, P. syringae pv. phaseolicola $1448 \mathrm{~A}$, and $P$. syringae pv. syringae B728a constituting 36, 25, and $29 \%$ of the total genome size, respectively (Table 1 ). These percentages are higher than the levels of variability determined from pairwise BLASTP analysis of individual open reading frames (ORF) (Feil et al. 2005; Joardar et al. 2005b), consistent with the fact that VR defined here encompass both unique regions and conserved genes either lacking syntenic conservation or conserved and acquired during ancient horizontal transfer. Of the $121 \mathrm{VR}$ identified 
among the three genomes, 109 were identified on the basis of both compositional deviation and syntenic disruption, 11 by Alien _hunter alone and eight by syntenic disruption alone. The high level of correspondence between locations of compositional deviation and gaps in genome alignment supports the utility of Alien_hunter and related statistical methods as tools for automated identification of putative VR.

As shown in Table 1, VR can be classified on the basis of their representation in the three genomes, where "unique" corresponds to regions found only in a single genome, "conserved" corresponds to those conserved in content but exhibiting deviation in sequence composition as determined by Alien_hunter, and "hotspot" refers to regions exhibiting either divergent content or compositional deviation or both in all three genomes. "Partial" indicates that a given region exhibits syntenic divergence or compositional deviation or both in two of the three genomes, and "boundary" refers to regions for which synteny cannot be established owing to its location at a site of genome rearrangement. Consistent with its overall larger genome size, DC3000 has both the largest number of VR and the highest percentage of its genome exhibiting variable content, reflected chiefly in a greater number of unique insertions and larger insertion sizes at conserved "hotspots" (Table 1). In contrast, 1448A has only one unique insertion (VR 32) and B728a none, though B728a contains two sizable insertions in boundary regions (VR 68 and 90), accounting for most of its variable genome in this category. The three genomes share eleven conserved regions.

It has been previously demonstrated that REP sequences preferentially segregate with the syntenically conserved core genome (Paulsen et al. 2005) and represent hotspots for genomic rearrangement (Tobes and Pareja 2006). To evaluate placement of REP sequences relative to core and VR, a hidden Markov model based on sequences described by Tobes and Pareja (2005) was constructed and used to search for REP sequences in the $P$. syringae pv. tomato DC3000 chromosome (Tobes and Pareja 2005). Of the 368 predicted REP sequences, $89 \%$ segregated with the predicted core regions, providing additional support for the core genome predictions in DC3000. Locations of REP sequences have been recently added to the DC3000 genome annotation at NCBI.

It should be noted that variables contributing to compositional variation have a tendency to ameliorate over time, such that more ancient horizontal transfer events are detected with less sensitivity (Lawrence and Ochman 1997). Regions of compositional deviation identified by Alien_hunter may also reflect sequence biases associated with function such as the high inci- dence of GC-rich hydrophobic amino-acid codons associated with membrane proteins. Furthermore, it should neither be assumed that the predicted flexible regions have arisen from single insertions nor that the boundaries given necessarily correspond to the locations of discrete insertion events. As is evident upon examination of the larger flexible regions, many of these regions are the result of multiple overlapping insertions, disruptions, and duplications. Systematic identification of regions transferred during independent events has proven extremely difficult.

\section{Locations of virulence and host-association genes relative to the core and flexible genome.}

A map of gene locations and corresponding locus tags relative to the numbered VR is shown in Table 2. P. syringae pv. tomato DC3000 "hop islands," described in previous deletion analyses, are also indicated (Wei et al. 2007). As a general observation, regulatory factors preferentially segregate with the core genome, including the recently described two-component regulatory system clusters, orphaned components, and hybrids, of which 82 of 107 are found in the core regions, and an additional 14 syntenically conserved within VR (Lavin et al. 2007). In contrast, members of the HrpL regulon segregate almost exclusively with VR. Most other classes of virulence and hostassociation factors are distributed more evenly between the core and variable genomes. Analysis of gene location relative to the core and VR is described for various classes of virulence factors in the following sections, together with insights on the relative timing of gene acquisition and potentially significant linkages among loci.

The HrpL regulon is localized to VR with evidence for comobilization by some members. Members of the HrpL regulon represent the class of virulence genes most strongly segregating with the VR, although, when shared by different strains, their locations are generally syntenic. This phenomenon is observed for the $h r p / h r c$ cluster encoding the T3SS, previously shown to be of ancient association with the $P$. syringae lineage (Alfano et al. 2000) and identified here as variable on the basis of compositional deviation (VR 36 and 37). The conserved effector locus ( $a v r E$, hopMl, and hopAAl) is also of ancient association but was not identified by Alien_hunter, possibly owing to a greater degree of sequence amelioration.

Of the remaining hop genes present in all three strains, $h o p A F 1, I 1, A H 2$, and $A N 1$ are found in small regions of syntenic conservation within otherwise VR hotspots. Likewise, hopAS1, AE1, AB1, AJ1, AT1, AG1, AH2, and AI1, shared by two of the three strains, are found at corresponding locations

Table 1. Number and size of variable regions identified by analysis of compositional deviation and syntenic disruption of Pseudomonas syringae pv. tomato DC3000, P. syringae pv. phaseolicola 1448A, and P. syringae pv. syringae B728a genomes ${ }^{\mathrm{y}}$

\begin{tabular}{|c|c|c|c|c|c|c|}
\hline \multirow[b]{2}{*}{ Variable region type } & \multicolumn{2}{|c|}{ P. syringae pv. tomato DC3000 } & \multicolumn{2}{|c|}{ P. syringae pv. phaseolicola 1448 A } & \multicolumn{2}{|c|}{ P. syringae pv. syringae $\mathrm{B} 728 \mathrm{a}$} \\
\hline & Number & Size $(\mathbf{k b})$ & Number & Size $(\mathbf{k b})$ & Number & Size $(k b)$ \\
\hline Total (including plasmids) & $105(107)$ & $2,199(2340)$ & $85(87)$ & $1,562(1,746)$ & 78 & 1,751 \\
\hline Unique (including plasmids) & $19(21)$ & $271(412)$ & $1(3)$ & $17(201)$ & 0 & 0 \\
\hline Conserved $^{\mathrm{z}}$ & 11 & 93 & 11 & 93 & 11 & 95 \\
\hline Hotspot & 45 & 1,237 & 45 & 763 & 45 & 864 \\
\hline Partial & 18 & 173 & 19 & 297 & 10 & 128 \\
\hline Boundary & 12 & 425 & 10 & 392 & 12 & 664 \\
\hline
\end{tabular}

${ }^{\mathrm{y}}$ Unique regions are those with an insertion present in one genome but no compositional deviation and gaps in syntenic alignment or insertion of mobile DNA at the corresponding location in the other two genomes. Conserved regions are identified by Alien_hunter as having compositional deviation in all three genomes but without gaps in the syntenic alignment. Hotspot regions are those with gaps in syntenic alignment, compositional deviation, or mobile DNA, singly or in combination, at corresponding locations in all three genomes. The partial designation reflects regions with gaps in syntenic alignment, compositional deviation, or mobile DNA, singly or in combination, at corresponding locations in two of the three genomes. The boundary designation indicates regions located at the boundaries of the major genome rearrangements in which genomic material does not align with either flank, but relative synteny cannot be established in one or more pairwise alignments owing to the rearrangement.

${ }^{\mathrm{z}}$ The 2-kb difference in region size observed for the conserved regions in $P$. syringae pv. syringae B728a relative to P. syringae pv. tomato DC3000 and $P$. syringae pv. phaseolicola 1448A reflects a discrepancy in the predictions made by Alien_hunter. 
Table 2. Locations of virulence and other host-association factors relative to the variable genome regions (VR), listed in the order they occur in the Pseudomonas syringae pv. tomato DC3000 genome, and identified by analysis of compositional deviation and sequence alignment of the P. syringae pv. tomato DC3000, P. syringae pv. phaseolicola 1448A, and P. syringae pv. syringae B728a genomes

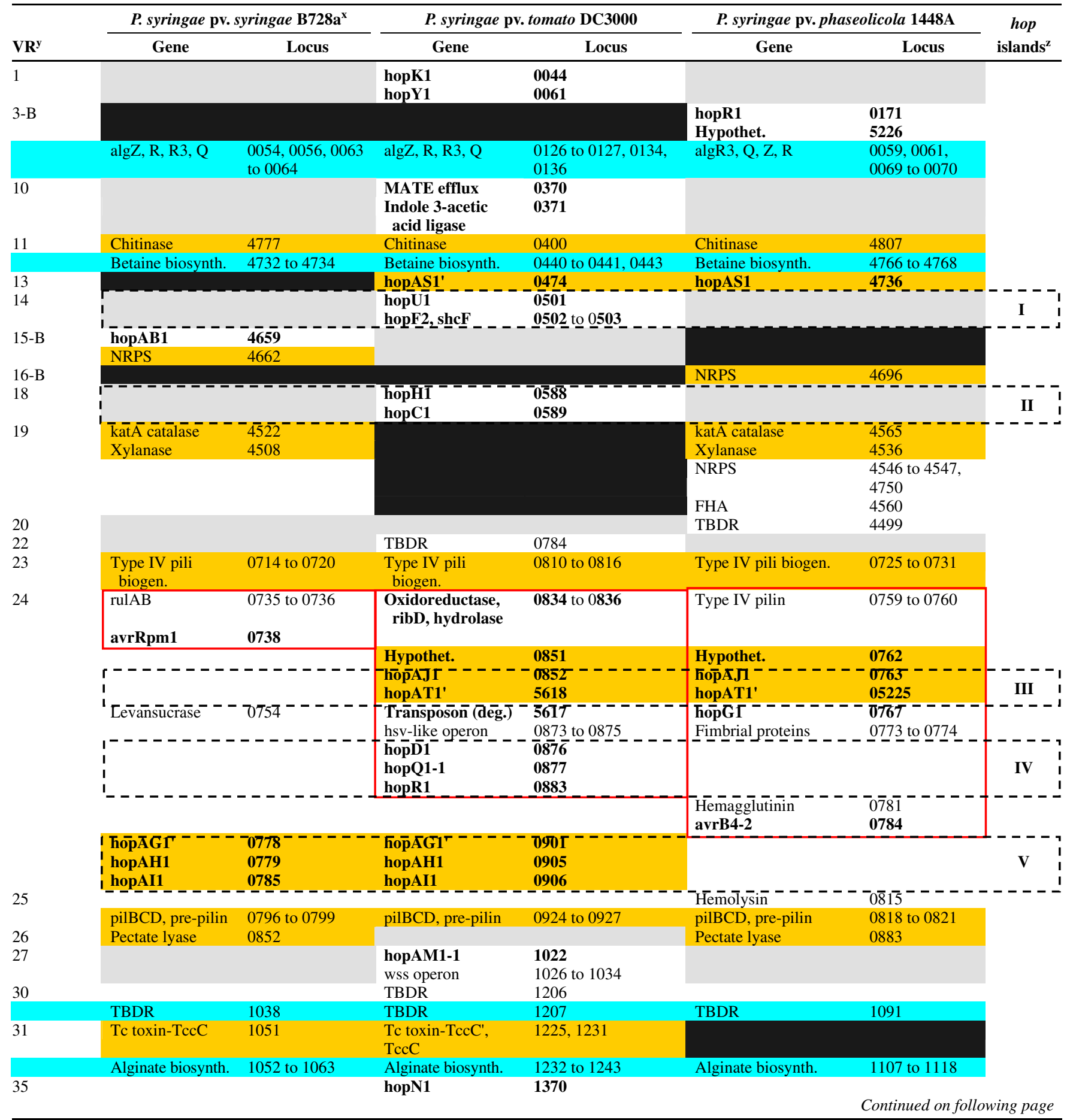

${ }^{\mathrm{x}}$ Names and locus tags of HrpL-regulated genes are indicated in bold type. biogen. = biogenesis, biosynth. = biosynthesis, deg. $=$ degenerate, EPS $=$ exopolysaccharides, FHA = filamentous hemagglutinin, hypothet. $=$ hypothetical, NRPS $=$ nonribosomal peptide synthase, polysacch. $=$ polysaccharide, put. $=$ putative, TBDR $=$ TonB-dependent receptor, resist. $=$ resistance, T2SS and T3SS, respectively $=$ type II and III secretion systems.

y Variable genome regions are listed in the order in which they occur relative to the P. syringae pv. tomato DC 3000 genome. Due to inversions and genome rearrangements, relative ordering of variable regions in P. syringae pv. phaseolicola $1448 \mathrm{~A}$ and $P$. syringae pv. syringae B728a should not be inferred from the numbers assigned. Individual cells are colored as follows: gold, syntenically conserved host-association factors within the variable genome regions; white, nonsyntenically conserved host-association factors within the variable genome regions; light gray, regions of divergent content within variable genome regions; blue, selected examples of syntenically conserved host-association factors in core genome regions; black, no corresponding variable region is present in the genome, due either to the absence of noncore material or because location at a genome rearrangement boundary prevents evaluation of syntenic correspondence. Locations of regions with similarity to integrative and conjugative elements (ICElands) are outlined in red. Variable regions located at the boundaries of the major genome rearrangements in one or more pairwise comparisons are indicated with a "B". Placement of the "B" variable regions in $P$. syringae pv. phaseolicola $1448 \mathrm{~A}$ and $P$. syringae pv. syringae B728a relative to the P. syringae pv. tomato DC3000 genome should not be inferred from the numbers assigned.

${ }^{\text {z }}$ Locations of "hop islands" in P. syringae pv. tomato DC3000 (Wei et al. 2007), are indicated by dashed lines and are labeled with Roman numerals. 
Table 2. Continued from preceding page

\begin{tabular}{|c|c|c|c|c|c|c|c|}
\hline \multirow[b]{2}{*}{$\mathbf{V R}^{\mathbf{x}}$} & \multicolumn{2}{|c|}{ P. syringae pv. syringae $\mathbf{B}^{2} 28 \mathrm{a}^{\mathrm{y}}$} & \multicolumn{2}{|c|}{ P. syringae pv. tomato DC3000 } & \multicolumn{2}{|c|}{ P. syringae pv. phaseolicola 1448 A } & \multirow{2}{*}{$\begin{array}{c}\text { hop } \\
\text { islands }{ }^{\mathrm{z}}\end{array}$} \\
\hline & Gene & Locus & Gene & Locus & Gene & Locus & \\
\hline & $\overline{\text { hop } \bar{A} \bar{A} 1-1}$ & $\overline{\mathbf{1 1 8} \overline{3}}$ & $\overline{\text { hорेĀ1-1 }}$ & $\overline{137 \overline{7}}$ & $\overline{\mathbf{h}} \overline{\mathrm{n}} \overline{\mathrm{A}} \overline{\mathrm{A}} \mathbf{1 - 1}$ & $\overline{\mathbf{1 2 6} \overline{3}}$ & \\
\hline & hrpW & 1184 & hrpW & 1373 & hrpW & 1264 & VI \\
\hline & i shcM, hopM1 & 1185 to $\mathbf{1 1 8 6}$ & shcM, hopM1 & 1374 to 1375 & shcM, hopM1 & 1265 to 1266 & \\
\hline & I shcE, avrE1 & 1187 to 1188 & _shcE, avrE1 & 1376 to 1377 & shcE, avrE1 & 1267 to 1268 & \\
\hline \multirow[t]{2}{*}{36} & 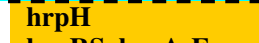 & $\overline{1} 1 \overline{89}$ & hrpH & $\overline{13} \overline{7} \overline{8}$ & $\overline{\mathbf{h}} \mathbf{r} \overline{\mathbf{p}} \overline{\mathbf{H}}^{------\bar{y}}$ & $\overline{\mathbf{1 2 6}} \overline{9}$ & \\
\hline & $\begin{array}{l}\text { hrpRS, hrpA-E, } \\
\text { hrpF-V }\end{array}$ & 1190 to 1202 & $\begin{array}{l}\text { hrpRS, hrpA-E, } \\
\text { hrpF-V }\end{array}$ & 1379 to 1391 & $\begin{array}{l}\text { hrpRS, hrpA-E, } \\
\text { hrpF-V }\end{array}$ & 1270 to 1281 & \\
\hline \multirow[t]{6}{*}{37} & hrpJ-hrcU operon & 1205 to 1216 & hrpJ-hrcU operon & 1392 to 1403 & hrpJ-hrcU operon & 1282 to 1293 & \\
\hline & hrpL, hrpK & 1217 to 1218 & hrpL, hrpK & 1404 to 1405 & hrpL, hrpK & 1294 to 1295 & \\
\hline & avrB3 & 1219 & & & & & \\
\hline & hopX1 & 1220 & & & hopX1 & 1296 & \\
\hline & hopZ3 & 1224 & hopB1 & 1406 & & & \\
\hline & Chaperone (put.) & 1225 & 3 hypothet. genes & 5622,1408 to 1409 & & & \\
\hline 38 & & & Levansucrase & 1453 & & & \\
\hline \multirow[t]{2}{*}{40} & hopAF1 & 3813 & hopAF1 & 1568 & hopAF1 & 1443 & \\
\hline & MarR regulator & 3737 & MarR regulator & 1645 & MarR regulator & 1519 & \\
\hline 42 & NRPS & 3722 & & & & & \\
\hline 44 & & & TBDR & 1855 & hopF3 & 3498 & \\
\hline \multirow[t]{5}{*}{48} & rulAB & 1884 to 1885 & & & & & \\
\hline & Hemolysin (put.) & 1886 & & & & & \\
\hline & hopH1 & 1889 & & & & & \\
\hline & hopAP1 & 1890 & & & & & \\
\hline & apbE family & 1900 & apbE family & 2105 & apbE family & 1855 & \\
\hline \multirow{2}{*}{49} & & & & & TBDR & 1870 & \\
\hline & Pyoverdin & 1945 to 1962 & Pyoverdin & 2134 to 2153 & Pyoverdin & 1910 to 1929 & \\
\hline 59 & & & & & TBDR & 2849 & \\
\hline 60 & & & T6SS & $\begin{array}{l}2539,2546,2549, \\
2553 \text { to } 2554\end{array}$ & & & \\
\hline \multirow[t]{2}{*}{62} & & & Yersiniabactin & 2595 to 2602 & Yersiniabactin & 2897 to 2904 & \\
\hline & & & TBDR & 2605,2607 & TBDR & 2892,2894 & \\
\hline \multirow[t]{2}{*}{64} & & & & & T3SS & $\begin{array}{l}2519 \text { to } 2521 \text {, } \\
2524, \\
2527 \text { to } 2530 \text {, } \\
2534 \text { to } 2538\end{array}$ & \\
\hline & Tc toxin-TccC & 2412 & hopP1 & 2678 & Tc toxin-TccC & 2571 & \\
\hline 66 & Phaseolotoxin (deg.) & 2549 to 2555 & & & Phaseolotoxin (deg.) & 2705 to 2711 & \\
\hline & Syringofactins & 2576 to 2577 & Syringofactins & 2829 to 2830 & NRPS (deg.) & 2729 & \\
\hline $67-B$ & & & & & TBDR & 2749 & \\
\hline & & & & & Achromobactin & 2751 to 2760 & \\
\hline $68-\mathrm{B}$ & TBDR & 2582 & TBDR & 2846 & & & \\
\hline & Achromobactin & 2584 to 2593 & TBDR & 2853 & & & \\
\hline & $\begin{array}{l}\text { Syringomycin/ } \\
\text { syringopeptin }\end{array}$ & 2608 to 2616 & & & & & \\
\hline & Streptomycin resist. & 2669 to 2670 & & & & & \\
\hline 70 & rulAB & 2761 to 2762 & & & & & \\
\hline & & & & & sheV-hopV1 & 2351 to 2352 & \\
\hline 72 & & & hopAB2 & 3087 & hopAB3' & 2294 & \\
\hline 74 & & & & & pel (deg.) & 2184 & \\
\hline & & & & & $\mathrm{T} 2 \mathrm{SS}$ & 2173 to 2183 & \\
\hline 75 & & & FHA & 3210 & & & \\
\hline & & & FHA (deg.) & 3214 & & & \\
\hline & Hemolysin & 3089 & FHA (intein) & 3229 & & & \\
\hline & aprA-like & 3163 & aprA-like & 3332 & aprA-like (deg.) & 3076 & \\
\hline 76 & & & & & avrB 4 - 1 & -3028 & \\
\hline & 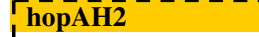 & $\overline{3123}$ & 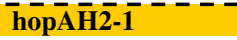 & $3 \overline{2} \overline{92}$ & hорА'̄ $\overline{2}$ & $\overline{30} \overline{36}$ & VI \\
\hline & $1-\ldots$ & & hopAH2-2 & 3293. & & & VII \\
\hline & $\overline{\mathrm{T}} 2 \mathrm{SS}$ & $314 \overline{1}$ to $315 \overline{1}$ & $\mathrm{~T} 2 \mathrm{SS}$ & 3307 to 3317 & $\overline{\mathrm{T}} 2 \mathrm{SS}$ & 3054 to 3064 & \\
\hline & Capsular polysacch. & $\begin{array}{l}3301 \text { to } 3308, \\
3231 \text { to } 3232\end{array}$ & Capsular polysacch. & $\begin{array}{l}3222 \text { to } 3227, \\
3449 \text { to } 3450\end{array}$ & Capsular polysacch. & $\begin{array}{r}3529 \text { to } 3534 \\
3150 \text { to } 3151\end{array}$ & \\
\hline & psl EPS & 3301 to 3311 & psl EPS & 3529 to 3539 & psl EPS & 3222 to 3232 & \\
\hline 80 & plcA1 lipase & 1823 & plcA1 lipase & 3648 & plcA1 lipase & 1783 & \\
\hline 81 & NRPS & 1790 to 1796 & & & NRPS & $\begin{array}{l}1749,1750 \\
1751\end{array}$ & \\
\hline 85 & Syringolin biosynth. & 1701 to 1706 & & & & & \\
\hline 90-B & & & $\mathrm{pgl}$ & 3960 & pgl (deg.) & 1530 & \\
\hline & RulAB & 1424 to 1425 & & & Shikimate kinase & 1525 & \\
\hline & $\mathrm{Cu}$ resist. & 1493 to 1498 & & & & & \\
\hline & $\begin{array}{l}\text { Type IV pilus } \\
\text { biogen. }\end{array}$ & 1509 to 1518 & & & & & \\
\hline 91-B & & & & & NRPS & 3750 & \\
\hline & & & & & $\begin{array}{l}\text { Oxidoreductase, rib } \\
\text { hydrolase }\end{array}$ & 3757 to 3759 & \\
\hline
\end{tabular}


Table 2. Continued from preceding page

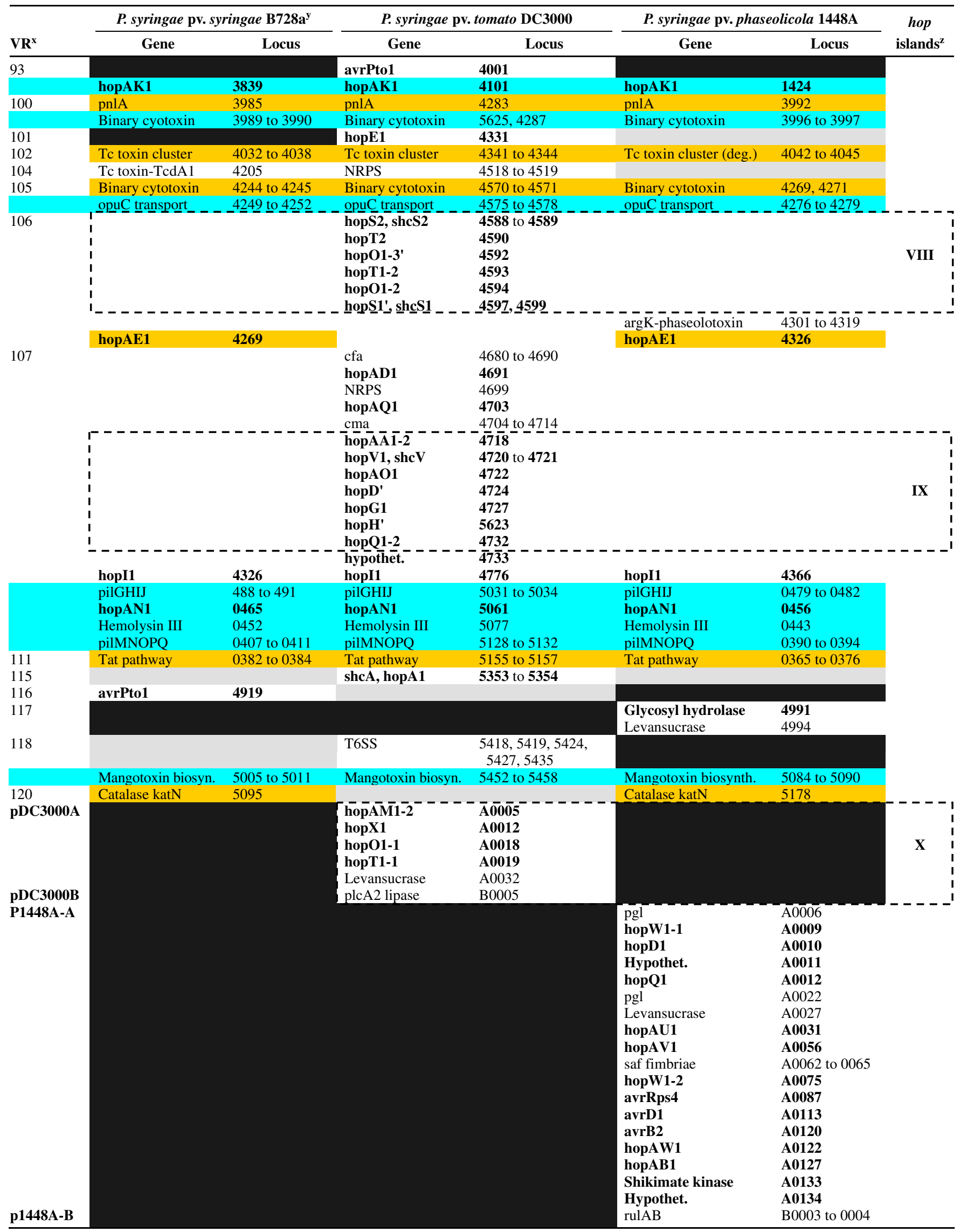


in the genomes in which they occur. Though the syntenic conservation of their flanking regions argues strongly for ancient association with the $P$. syringae lineage, several of these hop genes appear to have undergone more recent rearrangement. The hopAG1-AH1-AIl cluster in VR 24 $4_{\mathrm{Pto} D C 3000}$ is disrupted by an ISPssy insertion in hopAG1, hopAF $1_{\mathrm{Pto} \text { DC3000 }}$ in VR 40 is inverted relative to its orthologs in $P$. syringae pv. phaseolicola $1448 \mathrm{~A}$ and $P$. syringae pv. syringae $\mathrm{B} 728 \mathrm{a}$, and a duplication event appears to have occurred in $P$. syringae pv. tomato DC3000 resulting in the presence of a hopAH2 paralog immediately upstream of the syntenically conserved hopAH2-2 DC3000 in VR 76. The more ancient associations of avrE, hopIl, $A A 1, A J 1$, and $A K 1$ implied by gene synteny are consistent with the results of Rohmer and associates (2004) based on analysis of codon usage and GC content (Rohmer et al. 2004).

Among hop genes shared by two or more strains but lacking syntenic conservation are hopX1, found in the exchangeable effector locus (VR 37) of $P$. syringae pv. phaseolicola 1448A and $P$. syringae pv. syringae $\mathrm{B} 728 \mathrm{a}$, and on $P$. syringae pv. tomato DC3000 plasmid pDC3000A. Members of the hopAB family are also found in nonsyntenic locations, with hop $A B 1_{\mathrm{Pph}}$ 1448A present on $1448 \mathrm{~A}$ plasmid p1448A-A, hop $A B 1_{\text {Psy в728a }}$ in VR 15, and the more closely related hop $A B 2_{\mathrm{Pto}} \mathrm{DC} 3000$ and $A B 3_{\text {Pph } 1448 \mathrm{~A}}$ in VR 72. HopRl, G1, H1, V1, D1, and $Q 1$ are limited to two of the three genomes, with orthologs, excepting hop $V 1_{\mathrm{Pph} 1448 \mathrm{~A}}$, present in diverse VR (Table 2). Nonsyntenic distribution patterns are consistent with either independent acquisition by one or more strains or ancient acquisition followed by more recent intragenomic rearrangement.

While linkages observed for genes in the avrE-hopM1hopAA1, hopAJ-hopAT, and hopAG-AH-AI clusters are most likely due to vertical inheritance of ancient acquisitions, linkage patterns can also be observed for selected clusters of nonsytenically conserved hops and members of the Hrp-regulon, consistent with comobilization during either horizontal transfer or intragenomic duplication. Examples include the HrpLregulated operon PSPTO_0835 to 0837, which, together with 575 bp of conserved upstream DNA containing the HrpL promoter, is found at VR $24_{\mathrm{Pto} \text { DC3000 }}$ and $91_{\mathrm{Pph} \mathrm{1448A}}$, and members of the hopO and hopT families, found duplicated in VR $106_{\text {Pto }}$ DC3000 and on pDC3000A.

Comobilization also appears likely for hopD1 and hopQ1-1, located in VR 24 Pto DC3000 and on p1448A-A and conserved together with 340 and 90 bp of flanking DNA containing their HrpL promoters. The relatively close proximity of hopD and hop $Q$ orthologs in VR $107_{\mathrm{Pto} \mathrm{DC} 3000}$ raises the possibility that the two genes were comobilized to that region as well, with subsequent insertions of hopG1, hopH1, and two insertion sequences leading to the $6.4 \mathrm{~kb}$ presently separating the two genes. Interestingly, BLASTP analysis of hopDl ortholog sequences deposited in GenBank reveals the presence of flanking sequences similar to hopQ1 in both $P$. syringae phaseolicola 1302A (AJ277494) and Pantoea agglomerans pv. gypsophila (AF462346). The persistence of this linkage in diverse genera suggests that the biological roles and possible functional association of these two proteins may be influencing a broad range of plant-bacterial interactions. Though deletion of hopQ1-1 has been shown to expand host range for $P$. syringae pv. tomato DC3000 (Wei et al. 2007), neither the role of HopD1 nor the possibility of a HopD1-HopQ1 functional interaction has been explored.

In contrast to the members of the HrpL regulon, which strongly segregate with VR and are not generally represented across all three genomes (T3SS structural genes excepted), genes exhibiting reduced activity in the absence of transcription activators HrpRS, independent of HrpL-dependent activation, generally segregate with the conserved core of the $P$. sy- ringae genomes. Of the 60 genes thus identified (Lan et al. 2006), only 24 are present in VR, and all but 16 are syntenically conserved among the three genomes.

Toxins exhibit divergent distribution patterns depending on association with plant and insect pathogenesis. The most striking feature of toxin gene distribution is the divergent distribution patterns observed between those known only from plant pathogens and those with insect-active orthologs. Confirmed

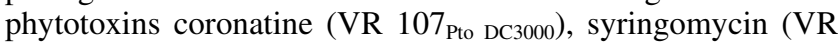
$107_{\text {Psy B 728a }}$ ), and phaseolotoxin (VR $106_{\mathrm{Pph} \mathrm{1448A}}$ ) are strain-specific in their localization, and the degenerate phaseolotoxin cluster is shared by only two of the three strains (VR 66).

In contrast, toxin genes shared with insect pathogens-the two $x a x A B$ loci (Vigneux et al. 2007), the mangotoxin cluster (Arrebola et al. 2007), and the toxin complex c cluster (Waterfield et al. 2001) —even when associated with VR, are syntenically conserved across all three genomes, suggestive of ancient association with the $P$. syringae lineage. A similar pattern is observed for the AprA metalloprotease and chitinase. Future investigation of this growing body of insect-associated virulence factors may reveal new perspectives on $P$. syringae niche adaptation. Does their presence indicate a long-standing and potentially ongoing ability to occupy an insect-associated niche as was recently demonstrated for the soft-rot phytopathogen Dickeya dadantii (Grenier et al. 2006)? Or do these virulence factors, like mangotoxin, have a broad spectrum of activity that $P$. syringae employs primarily in its interaction with plants?

Siderophores, adhesins, secretion pathways, and other virulence factors-segregation between core and variable genome points to possible sources of strain-specific interaction with host plants. The complex locus encoding genes for the biosynthesis and transport of the siderophore pyoverdine is syntenically conserved in the core $P$. syringae genome, consistent with its widespread presence in diverse pseudomonads. In contrast, achromobactin (P. syringae pv. phaseolicola 1448A and $P$. syringae pv. syringae $\mathrm{B} 728 \mathrm{a})$ and yersiniabactin $(P$. syringae pv. tomato DC3000 and P. syringae pv. phaseolicola 1448) loci are variable in their distribution, though the complexity of the regions in which they occur and their location near boundaries of genome rearrangements makes definitive judgment of syntenic conservation difficult. Genes encoding predicted TBDR (Blanvillain et al. 2007) are found closely linked to biosynthetic clusters for the three siderophore types. There appear to be over 15 TBDR syntenically conserved among the three genomes, with five and four additional unique TBDR present in VR of the DC3000 and 1448A genomes, respectively. Roles for the strain-specific TBDR have not been explored, but they could impact fitness at various stages of the bacterial-plant interaction through uptake of siderophores and other substrates.

In addition to those with characterized roles in toxin and siderophore production, seven other predicted nonribosomal peptide synthases are found in the $P$. syringae genomes. All are found in VR, with five conserved in neither location nor sequence, suggestive of possible strain-specific roles.

Comparison of factors with confirmed and potential involvement in adhesion also reveals significant differences among the three strains. All three contain syntenically conserved clusters encoding genes for biogenesis of alginate, Psl exopolysaccharides, type IV pili and, though apparently degenerate in $P$. syringae pv. phaseolicola 1448A, syringofactins. However, $P$. syringae pv. tomato DC3000 and 1448A encode additional complements of adhesin-related genes, segregating with the VR. In DC3000, these include the wss cellulose biosynthesis cluster (VR 27) and genes encoding two nondegenerate filamentous hemagglutinins (FHA) (VR 75), and, in 1448A, a 
plasmid-borne cluster of genes associated with biogenesis of saf atypical fimbriae and genes encoding a hemagglutinin (VR 24) and FHA (VR 19) distantly orthologous to those found in DC3000. The divergent repertoires of predicted adhesins may play determining roles in the relative attachment capacity observed for the three strains.

Among the more recently identified secretion pathways, the Tat pathway cluster, like the T3SS, is located in a region exhibiting compositional deviation but conserved in all three genomes (VR 111), as is the chromosomally borne gene for its substrate PlcA1 lipase. In contrast, the two T6SS (Mougous et al. 2006; Pukatzki et al. 2006) clusters are limited to DC3000 and are found in VR 60 and 118, suggesting a strain-specific role if shown to be functional.

While the majority of genes implicated in osmotic and oxidative stress tolerance are syntenically conserved, some differences are evident. $P$. syringae pv. phaseolicola 1448A and $P$. syringae pv. syringae B728a share two catalases (in VR 19 and 120) not found in P. syringae pv. tomato DC 3000 , and B728a encodes four orthologs of the $\operatorname{rul} B \mathrm{~B}$ DNA polymerase involved in repair of UV damage (VR 24, 48, 70, 90) not present in either DC3000 or 1448A. The additional copies of the rulAB locus have been previously implicated in the relative fitness of B728a on the epiphytic surface (Feil et al. 2005).

The collective distribution patterns for virulence and hostassociation genes support a model in which a commonly held foundation of syntenically conserved genes predisposes diverse strains for exploitation of the plant niche, with additional strainspecific repertoires, localized to the VR, shaping distinctive aspects of each strain's interaction with its plant hosts. That said, experimental confirmation of expression and functions are critical to the ultimate role assignments for individual gene products. As illustrated by the recent work with yersiniabactin, functional characterization can prove surprisingly difficult, even when bioinformatics has provided compelling hypotheses (Jones et al. 2007).

\section{The composition of VR is shaped \\ by diverse mobile genetic elements.}

Content of VR is typically shaped by the combined effects of rearrangement, disruption, deletion, and horizontal transfer (Gal-Mor and Finlay 2006; Hacker and Kaper 2000). Examination of the syntenically divergent VR reveals enrichment for mobile genetic elements, with $82 \%$ of the chromosomallyborne DC3000 mobile genetic elements located in VR. Among these are integrative and conjugative elements, prophages, phage integrases, and insertion elements (IS), analysis of which provides clues to the mechanisms underlying the composition of specific VR.

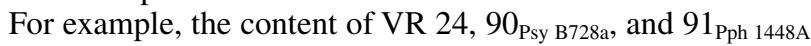
appears to have been largely shaped by integrative and conjugative elements (ICElands) (Burrus et al. 2002). PPHGI-1, the first ICEland characterized in $P$. syringae, was shown by Jackson and associates (2000) to excise from the genome of $P$. syringae pv. phaseolicola 1302A, resulting in deletion of the effector gene hopARl and expansion of the 1302A host range (Jackson et al. 2000; Pitman et al. 2005). Sequences orthologous to PPHGI-1 were also reported for $P$. syringae pv. tomato DC3000 and P. syringae pv. syringae B728a genomes (Pitman et al. 2005). As shown in Figure 1A, close comparison of PPHGI-1 with the sequenced $P$. syringae genomes reveals elements of the conserved ICEland framework in VR 24 for all three genomes, interspersed with variable content that includes numerous virulence-associated genes. VR 24 Pto DC3000 contains the most extended regions of similarity to previously characterized ICElands, interspersed with hopD1, Q1-1, AJ1, AT1, $R 1$ genes, and the HrpL-regulated operon PSPTO_0834 to
0837. VR 24 $4_{\mathrm{Pph}}$ 1448A carries the hopAJ1, hopAT1, hopG1, avrB4-2 genes as well as genes for two type IV pilins, two fimbrial proteins, and a hemagglutinin. Though the only conserved element of the ICEland framework in VR $24_{P_{\text {sy B }} 728 \mathrm{a}}$ is a phage integrase syntenically conserved with those in the other genomes, it is closely linked to avrRpml and one of the extra copies of rulAB previously described for B728a (Feil et al. 2005) (Fig. 1A).

VR $90_{\text {Psy B728a }}$ also includes regions of extended similarity with PPHGI-1 interspersed with genes predicted to confer copper resistance, a gene cluster for type IV pili biogenesis, and yet another of the extra $r u l A B$ loci. A phage integrase orthologous to that at the ICEland flank is present in VR $91_{\mathrm{Pph} 1448 \mathrm{~A}}$ and is associated with HrpL-regulated operon PSPTO_ 3759 to 3756, though no other conserved ICEland elements are present. The insertions at VR 24, 90, and 91 are associated with tRNAs, frequently cited as hotspots for insertion of phage integrases.

Distribution of ICEland sequences among diverse genomes was further explored by BLASTP comparison of DC3000 coding sequences against the predicted gene products of 58 other bacterial genomes, including 12 sequenced pseudomonads, representatives of all sequenced genera in the $\gamma$ and $\beta$-proteobacteria, and including completed sequences of the "canonical" phytopathogens Pectobacterium atrosepticum, Xyllela fastidiosa, Xanthomonas campestris pv. vesicatoria, Xanthomonas campestris pv. campestris ATCC 33913, Xanthomonas axonopodis pv. citri, Xanthomonas oryzae pv. oryzae, Burkholderia cenocepacia HI2424, and Ralstonia solanacearum. As shown in Figure 1B, BLASTP analysis reveals extended similarity with ICEland-associated genes, not only in P. syringae pv. syringae $\mathrm{B} 728 \mathrm{a}$ but also in $P$. aeruginosa PA14, Ralstonia metallidurans CH34, Burkholderia xenovorans LB400, Salmonella enterica subsp. enterica serovar Paratyphi A ATCC 9150, Photorhabdus luminescens subsp. laumondii TTO1, and phytopathogens Xanthomonas campestris pv. vesicatoria 85-10, and $P$. atrosepticum SCRI1043. Interestingly, the well-conserved ICEland found in $P$. atrosepticum encodes genes orthologous to the $c f a$ operon required for coronafacic acid biosynthesis in P. syringae pv. tomato DC3000 (Fig. 1A). The ICEland region identified in Xanthomonas campestris pv. vesicatoria 85 10 spans loci XCV2360-2414, with variable content corresponding to loci XCV2382 to XCV2385 and XCV2402 to $\mathrm{XCV} 2406$. None of the genes in this region have been implicated in virulence or host association.

Though several prophage clusters are found among the three P. syringae genomes, avrPtol appears to be the only prophageassociated virulence gene. AvrPtol $1_{\mathrm{Pto} \text { DC3000 }}$ is located immediately downstream of a nearly complete prophage cluster (VR

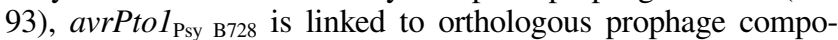
nents at a nonsyntenic location (VR 116), and comparison of avrPtol $_{\text {Pto DC3000 }}$ with the GenBank deposition for avrPtol $1_{\text {Pto }}$ JL1065 reveals that orthologous phage genes are also present im-

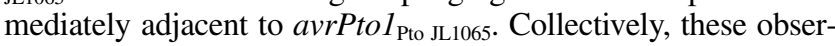
vations suggest that prophage-mediated mobilization is the dominant mechanism for intergenome mobilization of avrPtol.

hopHl and hopCl in VR $18_{\text {Pto DC3000 }}$ are linked to a putative prophage-derived pyocin insert between $\operatorname{trp} E$ and $\operatorname{trp} G$. Although this association is not found elsewhere in the three sequenced strains, analysis of GenBank deposition for the hopC orthologs in $P$. syringae pv. pisi race 1 (299A) (AJ277496) reveals a conserved arrangement between orthologs of hopH1, hopCl, and two genes immediately flanking. Whether this linkage results from vertical inheritance of a syntenically conserved region or pyocin-associated mobilization to diverse locations is presently unknown.

Insertion sequences acting in concert as composite transposons have also played a significant role in shaping the con- 
tent of VR. Ongoing analyses are revealing large numbers of gene fragments within the VR, linked in many instances to the locations of IS insertions. An example of this phenomenon is readily observable in VR $107_{\mathrm{Pto}} \mathrm{DC} 3000$, in which a hopD ortholog has been disrupted by an IS52 insertion and a hopH ortholog by an ISPsy4 insertion embedded in an insertion of ISPssy. Gene fragments resulting from IS insertions may hold the key to deciphering locations of discrete insertion events that have shaped VR content, as illustrated by $P$. syringae pv. tomato DC3000 VR 1, in which locations of the N and C-terminal fragments of an Mg-chelatase gene (PSPTO_0042 and PSPTO_0060) indicate that PSPTO_0043 to 0059 (which in-

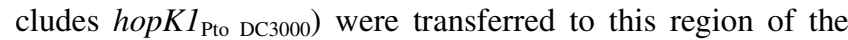
genome during a single mobilization event.

\section{VR are enriched for genes of low and} atypical distribution relative to other bacterial genomes.

Given the association of VR with confirmed virulence factors of nonuniform distribution and mobile elements promoting gene transfer and rearrangement, these regions are likely enriched for additional, as-yet-uncharacterized genes contributing to the bacterium-host interaction. To evaluate the distribution of predicted gene products in the $P$. syringae pv. tomato DC3000 VR among bacteria occupying diverse niches and of varying degrees of genetic relatedness, chromosomal and plasmid-borne coding sequences from DC3000 were compared with coding sequences of 41 other bacterial genomes, including 12 sequenced pseudomonads, representatives of all sequenced genera in the $\gamma$ and $\beta$-proteobacteria, and including completed sequences of the canonical phytopathogens. Results of BLASTP analyses are shown in the wheel diagrams in Figure 2, generated using Genome Diagram software (Pritchard et al. 2006). Locations of DC3000 VR are indicated in the outermost ring of the genome wheel. Similar representations of largescale genome comparison have previously been diagrammed for $P$. atrosepticum (Toth et al. 2006). A linear representation of BLASTP data for the DC3000 chromosome and plasmids, similar to the output shown in Figure $1 \mathrm{~B}$ is provided on the Pseudomonas-Plant Interaction website.

Fig. 1. Conservation between Pseudomonas syringae pv. tomato DC3000 (Pto) variable region 24 (VR \#24) and regions in other genomes. A, Comparison of DC3000 VR 24 with the integrative and conjugative element (ICEland) PPHGI-1 from P. syringae pv. phaseolicola 1302A and specified regions in $P$. syringae pv. phaseolicola $(P p h), P$. syringae pv. syringae (Psy), and Pectobacterium atrosepticum $(\mathrm{Pa}) . \mathrm{cfa}=$ coronafacic acid, $\mathrm{Cu}$ resis. = copper resistance, $\mathrm{HA}=$ hemagglutinin, hrpL-reg. = genes in the hrpL regulon, hyp. $=$ hypothetical, and $\mathrm{T} 4$ pili $=$ type 4 pili. Hops $\mathrm{AJ}$, AT, AR1, D1, G1, Q1, and R1 are shown without the hop gene designation. B, Presence of DC 3000 VR 24 orthologs in 58 other genera as determined by BLASTP analysis. Orthology of DC3000 loci (shown in sequential order on the $x$ axis) with open reading frames in selected bacterial genomes (listed on the $y$ axis) is indicated with colored squares, with the intensity of color proportional to the degree of sequence similarity. Mobile genetic elements are shown in red and members of the HrpL regulon in green. Pseudogenes, evaluated by BLASTN due to the absence of coding sequences in the genome annotation, are shown in black. Loci corresponding to ICEland components conserved between VR 24 Pto DC3000 and PPHGI-1 are indicated with asterisks. Genomes are grouped into four categories corresponding to pseudomonads, nonpseudomonad $\gamma$-proteobacteria, xanthomonads, and $\beta$-proteobacteria. Individual genomes showing orthology to the ICEland sequences are indicated as follows: $P$ syr $=P$. syringae pv. syringae $\mathrm{B} 728 \mathrm{a}, P f=P$. fluorescens $\mathrm{Pf}-5, P p=P$. putida $\mathrm{F} 1, P A 14=P$. aeruginosa $\mathrm{UCBPP}-\mathrm{PA} 14, P A 7=P$. aeruginosa $\mathrm{PA} 7, P \mathrm{~Pa}=$ ectobacterium atrosepticum SCRI1043, $\mathrm{Se}=$ Salmonella enterica subsp. enterica serovar Typhi CT18, Xcv $=X$. campestris pv. vesicatoria $85-10, X a c=X$. axonopodis pv. citri $306, B x=$ Burkholderia xenovorans $\mathrm{LB} 400, \mathrm{Rm}=$ Ralstonia metallidurans $\mathrm{CH} 34$. A complete listing of the 58 genomes screened is provided in the supplemental information published online.
Consistent with observations made for $P$. atrosepticum (Bell et al. 2004; Toth et al. 2006), the P. syringae pv. tomato DC3000 genome is a mosaic of broadly conserved regions interspersed with relatively open "rays" reflecting low or inconsistent conservation of component genes across the majority of genomes analyzed. VR generally correlate with locations of these open rays, though some also encompass areas of greater cross-genome conservation, particularly when component genes are members

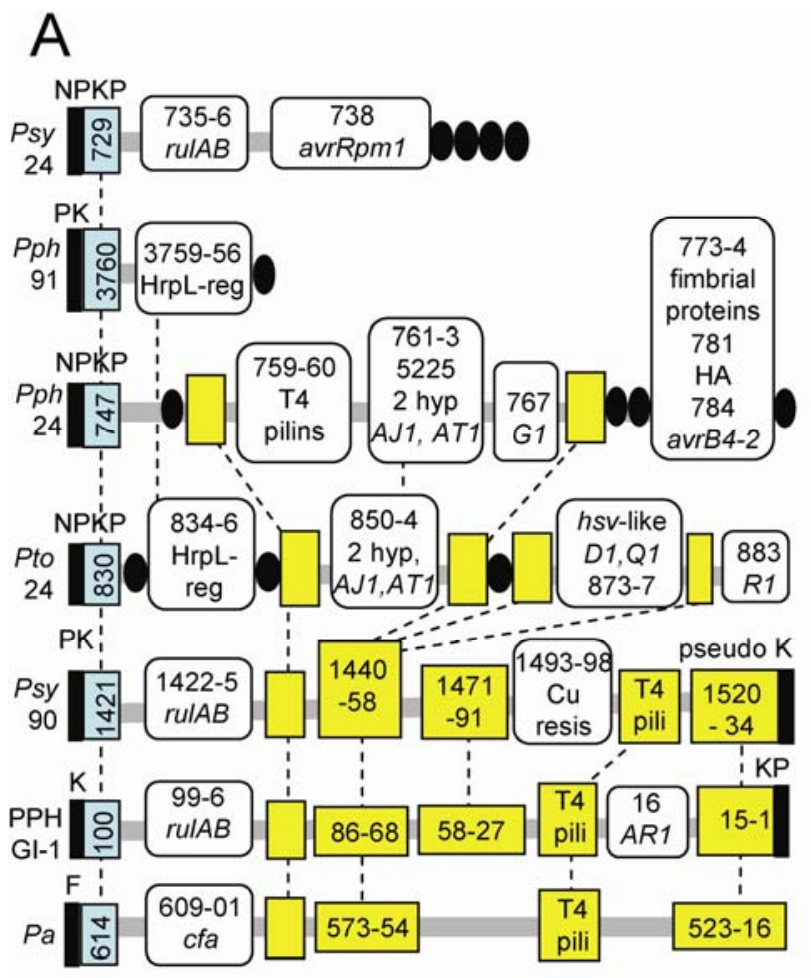

$\square$ Genes similar to those in the PPHGI-1 ICEland

- Insertion sequences

$\square$ Phage integrase

tRNAs

-- connects similar regions

B

VR \#24

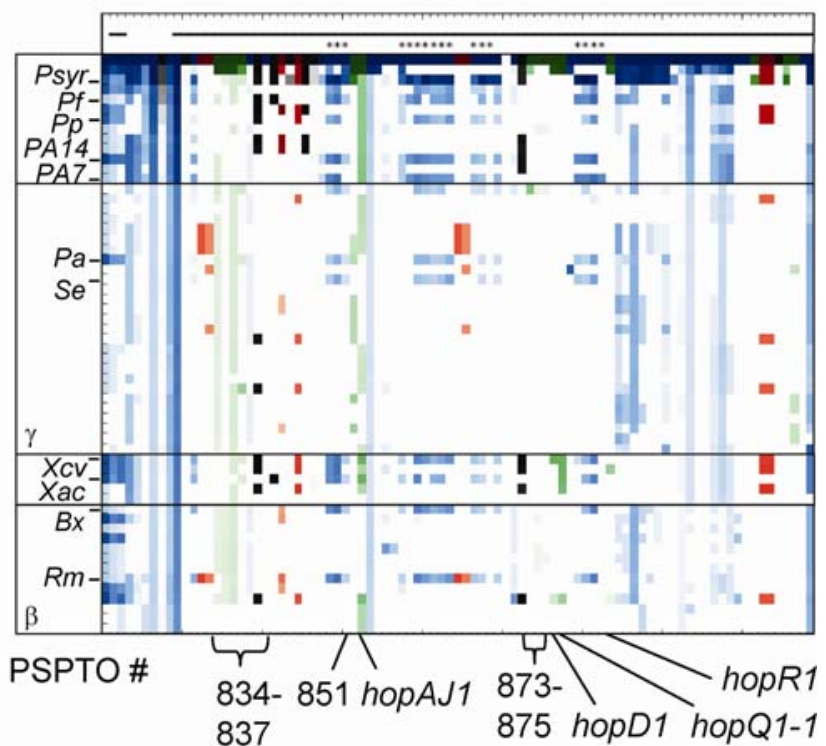



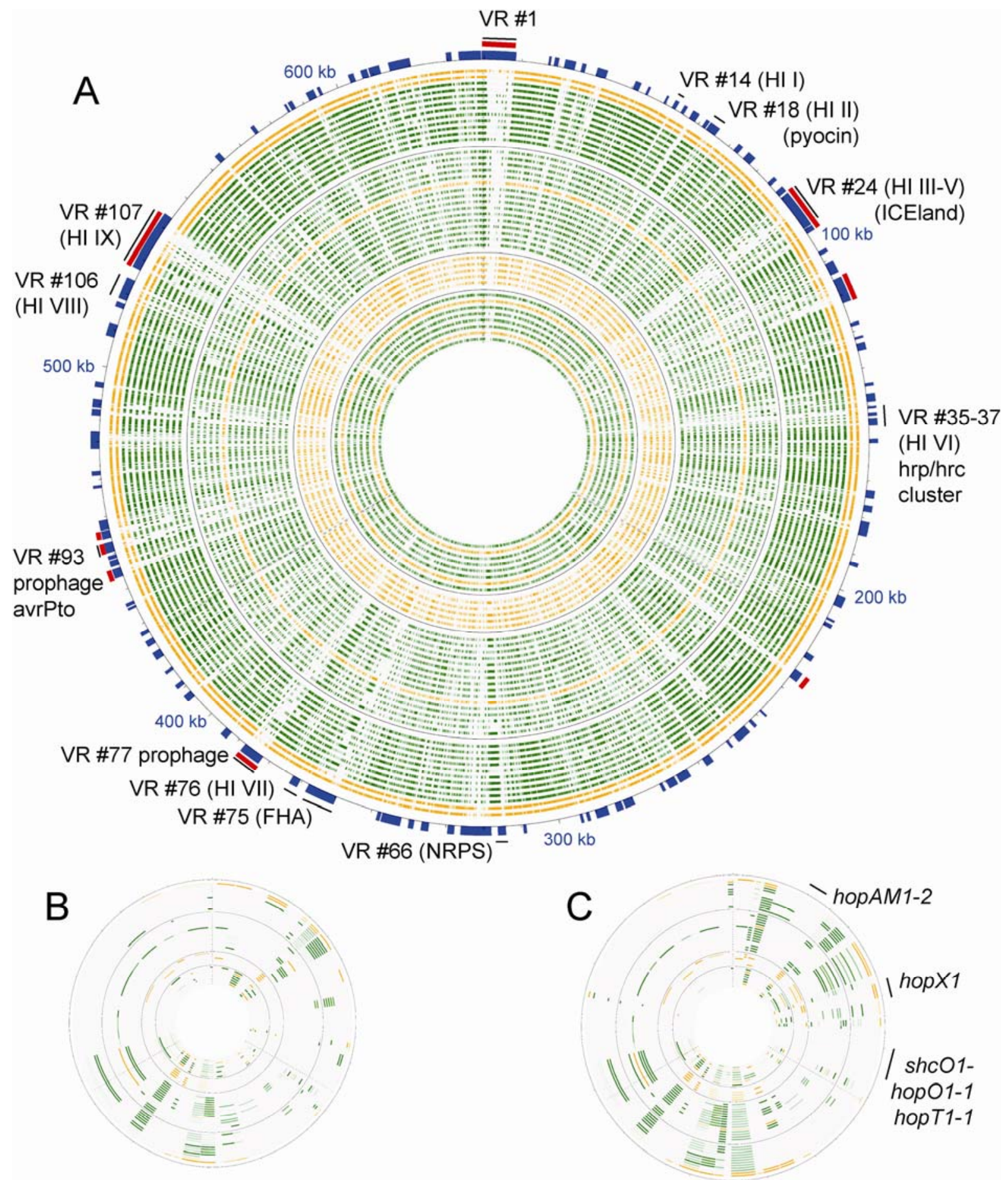

Fig. 2. Representation of Pseudomonas syringae pv. tomato DC3000 coding sequences in selected bacterial genomes as determined by BLASTP analysis of A, the DC3000 chromosome (NC_004578), B, DC3000 plasmid pDC3000B (NC_004632), and C, DC3000 plasmid pDC3000A (NC_004633). A, The outermost ring represents DC3000, with purple bars on the chromosome wheel indicating locations of variable regions. Presence of orthologs in other genomes is indicated on the remaining rings, with intensity of color proportional to the degree of sequence similarity. Locations of the DC3000 hop islands are shown (Wei et al. 2007), and regions enriched for genes found in two or fewer of the genomes screened are indicated with red bars. Genomes are grouped into four categories corresponding to pseudomonads, nonpseudomonad $\gamma$-proteobacteria, xanthomonads, and $\beta$-proteobacteria, with each category delineated by a solid gray line. The complete list of genomes from outer to innermost ring are as follows. Pseudomonads: 1, P. syringae pv. phaseolicola 1448A; 2, P. syringae pv. syringae B728a; 3 , P. fluorescens PfO-1; 4, P. fluorescens Pf-5; 5, P. putida KT2440; 6, P. putida F1; 7, P. entomophila L48; 8, P. stutzeri A1501; 9, P. mendocina YMP; 10, P. aeruginosa UCBPP-PA14; 11, P. aeruginosa PAO1; 12, P. aeruginosa PA7. Nonpseudomonad $\gamma$-proteobacteria: 13, Photorhabdus luminescens subsp. laumondii TTO1, 14. Shewanella frigidimarina, 15. Shewanella sp. MR-4, 16. Yersinia pseudotuberculosis IP 32953, 17. Yersinia pestis Antiqua; 18, Pectobacterium atrosepticum SCRI1043; 19, Salmonella enterica subsp. enterica serovar Choleraesuis SC-B67; 20, Salmonella enterica subsp. enterica serovar Typhi CT18; 21, Salmonella enterica subsp. enterica serovar Paratyphi A ATCC 9150; 22, Escherichia coli O157:H7 EDL933; 23, Escherichia coli UTI89; 24, Escherichia coli K12; 25, Vibrio vulnificus YJ016; 26, Vibrio cholerae O1 biovar eltor N16961; 27, Shigella flexneri 5 8401; 28, Aeromonas hydrophila subsp. hydrophila ATCC 7966. Xanthomonads: 29, X. campestris pv. vesicatoria 85-10; 30, X. campestris pv. campestris ATCC 33913; 31, X. axonopodis pv. citri 306; 32, X. oryzae pv. oryzae MAFF 311018; 33, Xylella fastidiosa Temecula1. $\beta$-proteobacteria; 34, Burkholderia xenovorans LB400; 35, Burkholderia cenocepacia HI2424; 36, Burkholderia thailandensis E264; 37, Burkholderia mallei ATCC 23344; 38, Ralstonia metallidurans CH34; 39, Ralstonia eutropha JMP134; 40, Ralstonia solanacearum GMI1000; 41, Bordetella bronchiseptica RB50. Canonical phytopathogens are shown in orange. 
of broadly conserved families. Examples include the genes encoding nonribosomal peptide synthase and filamentous hemagglutinin associated with VR 66 and 75, respectively, that elicit strong BLASTP hits from family members in many other species (Fig. 2A). As with the VR on the chromosomes, the plasmid coding sequences also exhibit low and idiosyncratic conservation with the contents of other genomes. Altogether, there are 832 DC3000 coding sequences with orthologs in no more than two of the 41 genomes analyzed. Of these, 438 are unique to DC3000 and 135 are limited to the three sequenced $P$. syringae genomes, representing not only candidate genes for strain and species-specific host interaction factors but also a valuable population of potential molecular markers for use in genome-based diagnostics (Vieira et al. 2007). Ongoing genome sequencing of additional $P$. syringae strains and other pseudomonads is expected to further refine the pools of strain- and species-specific genes. VR particularly enriched for genes of limited distribution include VR 1, 24, and 107 (Fig. 2A).

Aside from the virulence genes and mobile elements already noted, what functional information is available for genes in the VR? For the most part, very little is known, with over $30 \%$ of the genes in VR presently annotated as "hypothetical" or "conserved hypothetical." While the present review focuses on distribution patterns observed for known virulence-associated genes, future work will involve analysis of expression and distribution patterns for this uncharacterized reservoir of potential host-association genes. An important first step is represented by the ongoing direct sequencing of the $P$. syringae pv. tomato DC3000 transcriptome. This information on DC3000 transcripts is not only providing confirmation for gene products identified by orthology, such as the XaxAB toxins, but is also confirming expression and significantly refining coordinates for those genes lacking functional annotation (M. Filiatrault, personal communication). Complementary data obtained by shotgun proteomics methods confirm the expression of proteins encoded by what have, until now, been known only as hypothetical genes based on machine-generated ORF calls (D. J. Schneider, personal communication). These data, to be added to the annotation records at NCBI, will provide a sound experimental basis for accurate annotation of orthologs in strains and species with genome sequencing planned or underway and pave the way for meaningful investigation of their distribution among diverse bacteria and potential roles in the host-pathogen interaction.

\section{Summary.}

Advances in $P$. syringae gene characterization made since deposition of the original genome sequences for DC3000, 1448a, and B728a are broadening the current understanding of factors implicated in virulence and survival in the plant-associated niche.

To explore the relationship between virulence gene location and genome structure, a systematic approach for genome structure characterization was developed, incorporating compositional deviation and divergence in genome alignment. This approach, used here to generate a map of core regions and VR for the $P$. syringae genomes, is readily applicable to other sets of related genomes.

Analysis of the locations of virulence factors relative to the $P$. syringae genome map reveals strong segregation of the HrpL regulon with VR, divergent distribution patterns for toxin genes depending on their association with plant or insect pathogenesis, and patterns of distribution for other virulence genes that highlight potential sources of strain-to-strain difference in host interaction.

A subset of the VR contain dense mosaics of mobile genetic elements including phage, insertion sequences, and ICElands interspersed with gene fragments resulting from their activity. Ongoing identification of gene fragments coupled with future comparisons with additional $P$. syringae genomes will allow researchers to more clearly distinguish the individual genome rearrangement events that have shaped genome structure.

BLASTP analysis of $P$. syringae pv. tomato DC3000 genes with 41 other sequenced genomes reveals that the VR are enriched for genes with limited distribution and little or no functional characterization. Their presence in regions of high gene turnover and horizontal transfer suggests a possible role in unexplored strategies of adaptation to host and other environmental niches. Further characterization will be accomplished by comparison with the full range of genes and functional motifs available in public databases, together with application of proteomics data and transcriptome mapping to verify expression and refine annotated boundaries.

The resulting high-value annotation record for DC3000 will represent an invaluable resource for in-depth experimental characterization of the biological roles of expressed but functionally uncharacterized genes in the VR and comparison of gene repertoire and syntenic arrangement with those of $P$. syringae genomes currently being sequenced.

Since publication of its genome sequence in 2003, the significance of $P$. syringae pv. tomato DC3000 as a model system has been repeatedly reinforced by extensive characterization of virulence determinants, large-scale bioinformatic analyses, and structural characterization of gene products by researchers in diverse fields. Ongoing curation of its genome annotation through incorporation of new data such as those reviewed here is vital to the continuing role of DC3000 as a model system for experimental investigation and a model annotation record upon which future $P$. syringae genome annotations can be based.

\section{ACKNOWLEDGMENTS}

This work was supported by the National Science Foundation Plant Genome Research Program cooperative agreement DBI-0605059. C. R. Myers acknowledges support from the United State Department of Agriculture-Agricultural Research Service project 1907-21000-027-03. We thank G. A. DeClerck for assistance in computational analyses and two external reviewers for their exceptionally careful reading and incisive comments.

\section{LITERATURE CITED}

Abramovitch, R. B. and Martin, G. B. 2005. AvrPtoB: A bacterial type III effector that both elicits and suppresses programmed cell death associated with plant immunity. FEMS (Fed. Eur. Microbiol. Soc.) Microbiol. Lett. 245:1-8.

Alfano, J. R., Charkowski, A. O., Deng, W.-L., Badel, J. L., PetnickiOcwieja, T., van Dijk, K., and Collmer, A. 2000. The Pseudomonas syringae Hrp pathogenicity island has a tripartite mosaic structure composed of a cluster of type III secretion genes bounded by exchangeable effector and conserved effector loci that contribute to parasitic fitness and pathogenicity in plants. Proc. Natl. Acad. Sci. U.S.A. 97:48564861 .

Altschul, S. F., Gish, W., Miller, W., Myers, E. W., and Lipman, D. J. 1990. Basic local alignment search tool. J. Mol. Biol. 215:403-410.

Arrebola, E., Cazorla, F. M., Duran, V. E., Rivera, E., Olea, F., Codina, J. C., Perez-Garcia, A., and de Vicente, A. 2003. Mangotoxin: A novel antimetabolite toxin produced by Pseudomonas syringae inhibiting ornithine/arginine biosynthesis. Physiol. Mol. Plant Pathol. 63:117-127.

Arrebola, E., Cazorla, F. M., Romero, D., Perez-Garcia, A., and de Vicente, A. 2007. A nonribosomal peptide synthetase gene ( $m g o A)$ of Pseudomonas syringae pv. syringae is involved in mangotoxin biosynthesis and is required for full virulence. Mol. Plant-Microbe Interact. 20:500-509.

Beck, B. J., and Downs, D. M. 1998. The $a p b E$ gene encodes a lipoprotein involved in thiamine synthesis in Salmonella typhimurium. J. Bacteriol. 180:885-891.

Badel, J. L., Shimizu, R., Oh, H.-S., and Collmer, A. 2006. A Pseudomonas syringae pv. tomato avrE1/hopM1 mutant is severely reduced in 
growth and lesion formation in tomato. Mol. Plant-Microbe Interact. 19:99-111.

Bell, K. S., Sebaihia, M., Pritchard, L., Holden, M. T., Hyman, L. J., Holeva, M. C., Thomson, N. R., Bentley, S. D., Churcher, L. J., Mungall, K., Atkin, R., Bason, N., Brooks, K., Chillingworth, T., Clark, K., Doggett, J., Fraser, A., Hance, Z., Hauser, H., Jagels, K., Moule, S., Norbertczak, H., Ormond, D., Price, C., Quail, M. A., Sanders, M., Walker, D., Whitehead, S., Salmond, G. P., Birch, P. R., Parkhill, J., and Toth, I. K. 2004. Genome sequence of the enterobacterial phytopathogen Erwinia carotovora subsp. atroseptica and characterization of virulence factors. Proc. Natl. Acad. Sci. U.S.A. 101:11105-11110.

Bender, C. L., Alarcon-Chaidez, F., and Gross, D. C. 1999. Pseudomonas syringae phytotoxins: Mode of action, regulation, and biosynthesis by peptide and polyketide synthetases. Microbiol. Mol. Biol. Rev. 63:266292.

Berti, A. D., Greve, N. J., Christensen, Q. H., and Thomas, M. G. 2007. Identification of a biosynthetic gene cluster and the six associated lipopeptides involved in swarming motility of Pseudomonas syringae pv. tomato DC3000. J. Bacteriol. 189:6312-6323

Blanvillain, S., Meyer, D., Lauber, E., and Arlat, M. 2007. Plant carbohydrate scavenging through TonB-dependent receptors: A feature shared by phytopathogenic and aquatic bacteria. PLoS ONE 2:e224. Published online.

Boncompagni, E., Osteras, M., Poggi, M.-C., and le Rudulier, D. 1999. Occurrence of choline and glycine betaine uptake and metabolism in the family rhizobiaceae and their roles in osmoprotection. Appl. Environ. Microbiol. 65:2072-2077.

Bretz, J. R., Mock, N. M., Charity, J. C., Zeyad, S., Baker, C. J., and Hutcheson, S. W. 2003. A translocated protein tyrosine phosphatase of Pseudomonas syringae pv. tomato DC3000 modulates plant defence response to infection. Mol. Microbiol. 49:389-400.

Bronstein, P. A., Marrichi, M., Cartinhour, S., Schneider, D. J., and DeLisa, M. P. 2005. Identification of a twin-arginine translocation system in Pseudomonas syringae pv. tomato DC 3000 and its contribution to pathogenicity and fitness. J. Bacteriol. 187:8450-8461.

Buell, C. R., Joardar, V., Lindeberg, M., Selengut, J., Paulsen, I. T., Gwinn, M. L., Dodson, R. J., Deboy, R. T., Durkin, A. S., Kolonay, J. F., Madupu, R., Daugherty, S., Brinkac, L., Beanan, M. J., Haft, D. H., Nelson, W. C., Davidsen, T., Zafar, N., Zhou, L., Liu, J., Yuan, Q., Khouri, H., Fedorova, N., Tran, B., Russell, D., Berry, K., Utterback, T., Van Aken, S. E., Feldblyum, T. V., D'Ascenzo, M., Deng, W. L., Ramos, A. R., Alfano, J. R., Cartinhour, S., Chatterjee, A. K., Delaney, T. P., Lazarowitz, S. G., Martin, G. B., Schneider, D. J., Tang, X., Bender, C. L., White, O., Fraser, C. M., and Collmer, A. 2003. The complete genome sequence of the Arabidopsis and tomato pathogen Pseudomonas syringae pv. tomato DC3000. Proc. Natl. Acad. Sci. U.S.A. 100:10181-10186.

Burrus, V., Pavlovic, G., Decaris, B. and Guedon, G. 2002. Conjugative transposons: The tip of the iceberg. Mol. Microbiol. 46:601-610.

Carver, T. J., Rutherford, K. M., Berriman, M., Rajandream, M.-A., Barrell, B. G., and Parkhill, J. 2005. ACT: The Artemis comparison tool. Bioinformatics 21:3422-3423.

Chang, J. H., Urbach, J. M., Law, T. F., Arnold, L. W., Hu, A., Gombar, S., Grant, S. R., Ausubel, F. M., and Dangl, J. L. 2005. A high-throughput, near-saturating screen for type III effector genes from Pseudomonas syringae. Proc. Natl. Acad. Sci. U.S.A. 102:2549-2554.

Chatterjee, A., Cui, Y., and Chatterjee, A. K. 2002. Regulation of Erwinia carotovora hrpLEcc sigma-LEcc, which encodes an extracytoplasmic function subfamily of sigma factor required for expression of the HRP regulon. Mol. Plant-Microbe Interact. 15:971-980.

Chatterjee, A., Cui, Y., Hasegawa, H., and Chatterjee, A. K. 2007. PsrA, the Pseudomonas sigma regulator, controls regulators of epiphytic fitness, quorum-sensing signals, and plant interactions in Pseudomonas syringae pv. tomato strain DC3000. Appl. Environ. Microbiol. 73:36843694.

Chang, W.-S., van de Mortel, M., Nielsen, L., Nino de Guzman, G., Li, X. and Halverson, L. J. 2007. Alginate production by Pseudomonas putida creates a hydrated microenvironment and contributes to biofilm architecture and stress tolerance under water-limiting conditions. J. Bacteriol. 189:8290-8299.

Chen, C., and Beattie, G. A. 2007. Characterization of the osmoprotectant transporter OpuC from Pseudomonas syringae and demonstration that CBS domains are required for its osmoregulatory function. J. Bacteriol. 189:6901-6912.

Chen, C., and Beattie, G. A. 2008. Pseudomonas syringae BetT is a low affinity choline transporter that is responsible for superior osmoprotection by choline over glycine betaine. J. Bacteriol. 190:2717-2715.

Donadio, S., Monciardini, P., and Sosio, M. 2007. Polyketide synthases and nonribosomal peptide synthetases: The emerging view from bacterial genomics. Nat. Prod. Rep. 24:1073-1109.
Espinosa, A., Guo, M., Tam, V. C., Fu, Z. Q., and Alfano, J. R. 2003. The Pseudomonas syringae type III-secreted protein HopPtoD2 possesses protein tyrosine phosphatase activity and suppresses programmed cell death in plants. Mol. Microbiol. 49:377-387.

Feil, H., Feil, W. S., Chain, P., Larimer, F., DiBartolo, G., Copeland, A., Lykidis, A., Trong, S., Nolan, M., Goltsman, E., Thiel, J., Malfatti, S., Loper, J. E., Lapidus, A., Detter, J. C., Land, M., Richardson, P. M., Kyrpides, N. C., Ivanova, N., and Lindow, S. E. 2005. Comparison of the complete genome sequences of Pseudomonas syringae pv. syringae B728a and pv. tomato DC3000. Proc. Natl. Acad. Sci. U.S.A. 102:11064-11069.

Ferreira, A. O., Myers, C. R., Gordon, J. S., Martin, G. B., Vencato, M., Collmer, A., Wehling, M. D., Alfano, J. R., Moreno-Hagelsieb, G., Lamboy, W. F., DeClerck, G., Schneider, D. J., and Cartinhour, S. W. 2006. Whole-genome expression profiling defines the HrpL regulon of Pseudomonas syringae pv. tomato DC3000, allows de novo reconstruction of the Hrp cis clement, and identifies novel coregulated genes. Mol. Plant-Microbe Interact. 19:1167-1179.

Fourie, D. 1998. Characterization of halo blight races on dry beans in South Africa. Plant Dis. 82:307-310.

Fouts, D. E., Abramovitch, R. B., Alfano, J. R., Baldo, A. M., Buell, C. R. Cartinhour, S., Chatterjee, A. K., D'Ascenzo, M., Gwinn, M. L., Lazarowitz, S. G., Lin, N. C., Martin, G. B., Rehm, A. H., Schneider, D. J., van Dijk, K., Tang, X., and Collmer, A. 2002. Genomewide identification of Pseudomonas syringae pv. tomato DC3000 promoters controlled by the HrpL alternative sigma factor. Proc. Natl. Acad. Sci. U.S.A. 99:2275-2280.

Fu, Z. Q., Guo, M., Jeong, B. R., Tian, F., Elthon, T. E., Cerny, R. L. Staiger, D., and Alfano, J. R. 2007. A type III effector ADP-ribosylates RNA-binding proteins and quells plant immunity. Nature 447:284-288.

Gal, M., Preston, G. M., Massey, R. C., Spiers, A. J., and Rainey, P. B. 2003. Genes encoding a cellulosic polymer contribute toward the ecological success of Pseudomonas fluorescens SBW25 on plant surfaces. Mol. Ecol. 12:3109-3121.

Gal-Mor, O., and Finlay, B. B. 2006. Pathogenicity islands: A molecular toolbox for bacterial virulence. Cell. Microbiol. 8:1707-1719.

Greenberg, J. T., and Vinatzer, B. A. 2003. Identifying type III effectors of plant pathogens and analyzing their interaction with plant cells. Curr. Opin. Microbiol. 6:20-28.

Grenier, A.-M., Duport, G., Pages, S., Condemine, G., and Rahbe, Y. 2006. The phytopathogen Dickeya dadantii (Erwinia chrysanthemi 3937) is a pathogen of the pea aphid. Appl. Environ. Microbiol. 72:1956-1965.

Guttman, D. S., Vinatzer, B. A., Sarkar, S. F., Ranall, M. V., Kettler, G. and Greenberg, J. T. 2002. A functional screen for the type III Hrp secretome of the plant pathogen Pseudomonas syringae. Science 295:1722-1726.

Hacker, J., and Kaper, J. B. 2000. Pathogenicity islands and the evolution of microbes. Annu. Rev. Microbiol. 54:641-679.

Hirano, S. S., and Upper, C. D. 2000. Bacteria in the leaf ecosystem with emphasis on Pseudomonas syringae-a pathogen, ice nucleus, and epiphyte. Microbiol. Mol. Biol. Rev. 64:624-653.

Hsiao, W. W. L., Ung, K., Aeschliman, D., Bryan, J., Finlay, B. B., and Brinkman, F. S. L. 2005. Evidence of a large novel gene pool associated with prokaryotic genomic islands. PLoS Genetics 1:e62. Published online.

Jackson, R. W., Mansfield, J. W., Arnold, D. L., Sesma, A., Paynter, C. D., Murillo, J., Taylor, J. D., and Vivian, A. 2000. Excision from tRNA genes of a large chromosomal region, carrying avrPphB, associated with race change in the bean pathogen, Pseudomonas syringae pv. phaseolicola. Mol. Microbiol. 38:186-197.

Jelenska, J., Yao, N., Vinatzer, B. A., Wright, C. M., Brodsky, J. L., and Greenberg, J. T. 2007. A J domain virulence effector of Pseudomonas syringae remodels host chloroplasts and suppresses defenses. Curr. Biol. 17:499-508.

Joardar, V., Lindeberg, M., Jackson, R. W., Selengut, J., Dodson, R., Brinkac, L. M., Daugherty, S. C., Deboy, R., Durkin, A. S., Giglio, M G., Madupu, R., Nelson, W. C., Rosovitz, M. J., Sullivan, S., Crabtree, J., Creasy, T., Davidsen, T., Haft, D. H., Zafar, N., Zhou, L., Halpin, R., Holley, T., Khouri, H., Feldblyum, T., White, O., Fraser, C. M., Chatterjee, A. K., Cartinhour, S., Schneider, D. J., Mansfield, J. Collmer, A., and Buell, C. R. 2005a. Whole-genome sequence analysis of Pseudomonas syringae pv. phaseolicola 1448A reveals divergence among pathovars in genes involved in virulence and transposition. J. Bacteriol. 187:6488-6498.

Joardar, V., Lindeberg, M., Schneider, D. J., Collmer, A., and Buell, C. R. 2005b. Lineage-specific regions in Pseudomonas syringae pv. tomato DC3000. Mol. Plant Pathol. 6:53-64.

Jones, A. M., Lindow, S. E., and Wildermuth, M. C. 2007. Salicylic acid, yersiniabactin, and pyoverdin production by the model phytopathogen Pseudomonas syringae pv. tomato DC3000: Synthesis, regulation, and 
impact on tomato and Arabidopsis host plants. J. Bacteriol. 189:67736786.

Karamanoli, K., and Lindow, S. E. 2006. Disruption of $N$-acyl homoserine lactone-mediated cell signaling and iron acquisition in epiphytic bacteria by leaf surface compounds. Appl. Environ. Microbiol. 72:76787686

Karlin, S. 2001. Detecting anomalous gene clusters and pathogenicity islands in diverse bacterial genomes. Trends Microbiol. 9:335-343.

Kloek, A. P., Verbsky, M. L., Sharma, S. B., Schoelz, J. E., Vogel, J., Klessig, D. F., and Kunkel, B. N. 2001. Resistance to Pseudomonas syringae conferred by an Arabidopsis thaliana coronatine-insensitive coil mutation occurs through two distinct mechanisms. Plant J. 26:509-522.

Kvitko, B. H., Ramos, A. R., Morello, J. E., Oh, H.-S., and Collmer, A. 2007. Identification of harpins in Pseudomonas syringae pv. tomato DC3000, which are functionally similar to HrpK1 in promoting translocation of type III secretion system effectors. J. Bacteriol. 189:80598072

Lamark, T., Kaasen, I., Eshoo, M. W., Falkenberg, P., McDougall, J., and Strom, A. R. 1991. DNA sequence and analysis of the bet genes encoding the osmoregulatory choline-glycine betaine pathway of Escherichia coli. Mol. Microbiol. 5:1049-1064.

Lan, L., Deng, X., Zhou, J., and Tang, X. 2006. Genome-wide gene expression analysis of Pseudomonas syringae pv. tomato DC3000 reveals overlapping and distinct pathways regulated by $h r p L$ and $h r p R S$. Mol. Plant-Microbe Interact. 19:976-987.

Landfald, B., and Strom, A. R. 1986. Choline-glycine betaine pathway confers a high level of osmotic tolerance in Escherichia coli. J. Bacteriol. 165:849-855

Laue, H., Schenk, A., Li, H., Lambertsen, L., Neu, T. R., Molin, S., and Ullrich, M. S. 2006. Contribution of alginate and levan production to biofilm formation by Pseudomonas syringae. Microbiology 152:29092918.

Lavin, J. L., Kiil, K., Resano, O., Ussery, D. W., and Oguiza, J. A. 2007. Comparative genomic analysis of two-component regulatory proteins in Pseudomonas syringae. BMC Genomics 8:397. Published online.

Lawrence, J. G., and Ochman, H. 1997. Amelioration of Bacterial Genomes: Rates of Change and Exchange. J. Mol. Evol. 44:383-397.

Liehl, P., Blight, M., Vodovar, N., Boccard, F., and Lemaitre, B. 2006. Prevalence of local immune response against oral infection in a Drosophila/Pseudomonas infection model. PLoS Pathogens 2:e56. Published online.

Lin, N. C., and Martin, G. B. 2007. Pto- and Prf-mediated recognition of AvrPto and AvrPtoB restricts the ability of diverse Pseudomonas syringae pathovars to infect tomato. Mol. Plant-Microbe Interact. 20:806815

Lindeberg, M., Cartinhour, S., Myers, C. R., Schechter, L. M., Schneider, D. J., and Collmer, A. 2006. Closing the circle on the discovery of genes encoding Hrp regulon members and type III secretion system effectors in the genomes of three model Pseudomonas syringae strains. Mol. Plant-Microbe Interact. 19:1151-1158.

Lopez-Solanilla, E., Bronstein, P. A., Schneider, A. R., and Collmer, A. 2004. HopPtoN is a Pseudomonas syringae Hrp type III secretion system cyseine protease effector that suppresses pathogen-induced necrosis associated with both compatible and incompatible plant interactions. Mol. Microbiol. 54:353-365.

Ma, L., Jackson, K. D., Landry, R. M., Parsek, M. R., and Wozniak, D. J. 2006. Analysis of Pseudomonas aeruginosa conditional Psl variants reveals roles for the Psl polysaccharide in adhesion and maintaining biofilm structure postattachment. J. Bacteriol. 188:8213-8221.

Maillard, J., Spronk, C. A., Buchanan, G., Lyall, V., Richardson, D. J., Palmer, T., Vuister, G. W., and Sargent, F. 2007. Structural diversity in twin-arginine signal peptide-binding proteins. Proc. Natl. Acad. Sci. U.S.A. 104:15641-15646.

Marco, M. L., Legac, J., and Lindow, S. E. 2005. Pseudomonas syringae genes induced during colonization of leaf surfaces. Environ. Microbiol. 7:1379-1391

Melotto, M., Underwood, W., Koczan, J., Nomura, K., and He, S. Y. 2006. Plant stomata function in innate immunity against bacterial invasion. Cell 126:969-980.

Miller, K. J., and Wood, J. M. 1996. Osmoadaptation by rhizosphere bacteria. Ann. Rev. Microbiol. 50:101-136.

Mole, B. M., Baltrus, D. A., Dangl, J. L., and Grant, S. R. 2007. Global virulence regulation networks in phytopathogenic bacteria. Trends $\mathrm{Mi}$ crobiol. 15:363-371.

Monier, J. M., and Lindow, S. E. 2003. Differential survival of solitary and aggregated bacterial cells promotes aggregate formation on leaf surfaces. Proc. Natl. Acad. Sci. U.S.A. 100:15977-15982.

Mougous, J. D., Cuff, M. E., Raunser, S., Shen, A., Zhou, M., Gifford, C. A., Goodman, A. L., Joachimiak, G., Ordonez, C. L., Lory, S., Walz, T., Joachimiak, A., and Mekalanos, J. J. 2006. A virulence locus of Pseu- domonas aeruginosa encodes a protein secretion apparatus. Science 312:1526-1530.

Nomura, K., Melotto, M., and He, S. Y. 2005. Suppression of host defense in compatible plant-Pseudomonas syringae interactions. Curr. Opin. Plant Biol. 8:361-368.

Oh, C.-S., Kim, J. F., and Beer, S. V. 2005. The Hrp pathogenicity island of Erwinia amylovora and identification of three novel genes required for systemic infection. Mol. Plant Pathol. 6:125-138.

Oh, H.-S., Kvitko, B. H., Morello, J. E., and Collmer, A. 2007. Pseudomonas syringae lytic transglycosylases co-regulated with the type III secretion system contribute to the translocation of effector proteins into plant cells. J. Bacteriol. 189:8277-8289.

Paulsen, I. T., Banerjei, L., Myers, G. S. A., Nelson, K. E., Seshadri, R., Read, T. D., Fouts, D. E., Eisen, J. A., Gill, S. R., Heidelberg, J. F., Tettelin, H., Dodson, R. J., Umayam, L., Brinkac, L., Beanan, M., Daugherty, S., DeBoy, R. T., Durkin, S., Kolonay, J., Madupu, R., Nelson, W., Vamathevan, J., Tran, B., Upton, J., Hansen, T., Shetty, J., Khouri, H., Utterback, T., Radune, D., Ketchum, K. A., Dougherty, B. A., and Fraser, C. M. 2003. Role of mobile DNA in the evolution of vancomycin-resistant Enterococcus faecalis. Science 299:2071-2074.

Paulsen, I. T., Press, C. M., Ravel, J., Kobayashi, D. Y., Myers, G. S., Mavrodi, D. V., DeBoy, R. T., Seshadri, R., Ren, Q., Madupu, R., Dodson, R. J., Durkin, A. S., Brinkac, L. M., Daugherty, S. C., Sullivan, S. A., Rosovitz, M. J., Gwinn, M. L., Zhou, L., Schneider, D. J., Cartinhour, S. W., Nelson, W. C., Weidman, J., Watkins, K., Tran, K., Khouri, H., Pierson, E. A., Pierson, L. S., 3rd, Thomashow, L. S., and Loper, J. E. 2005. Complete genome sequence of the plant commensal Pseudomonas fluorescens Pf-5. Nat. Biotechnol. 23:873-878.

Petnicki-Ocwieja, T., Schneider, D. J., Tam, V. C., Chancey, S. T., Shan, L., Jamir, Y., Schechter, L. M., Janes, M. D., Buell, C. R., Tang, X., Collmer, A., and Alfano, J. R. 2002. Genomewide identification of proteins secreted by the Hrp type III protein secretion system of Pseudomonas syringae pv. tomato DC3000. Proc. Natl. Acad. Sci. U.S.A. 99:7652-7657.

Petnicki-Ocwieja, T., van Dijk, K., and Alfano, J. R. 2005. The hrpK operon of Pseudomonas syringae pv. tomato DC3000 encodes two proteins secreted by the type III Hrp protein secretion system: HopB1 and HrpK, a putative type III translocator. J. Bacteriol. 187:649-663.

Pinheiro, V. B., and Ellar, D. J. 2007. Expression and insecticidal activity of Yersinia pseudotuberculosis and Photorhabdus luminescens toxin complex proteins. Cell. Microbiol. 9:2372-2380.

Pitman, A. R., Jackson, R. W., Mansfield, J. W., Kaitell, V., Thwaites, R., and Arnold, D. L. 2005. Exposure to host resistance mechanisms drives evolution of bacterial virulence in plants. Curr. Biol. 15:2230-2235.

Pritchard, L., White, J. A., Birch, P. R. J., and Toth, I. K. 2006. GenomeDiagram: A python package for the visualization of large-scale genomic data. Bioinformatics 22:616-617.

Pukatzki, S., Ma, A. T., Revel, A. T., Sturtevant, D., and Mekalanos, J. J. 2007. Type VI secretion system translocates a phage tail spike-like protein into target cells where it cross-links actin. Proc. Natl. Acad. Sci. U.S.A. 104:15508-15513.

Pukatzki, S., Ma, A. T., Sturtevant, D., Krastins, B., Sarracino, D., Nelson, W. C., Heidelberg, J. F., and Mekalanos, J. J. 2006. Identification of a conserved bacterial protein secretion system in Vibrio cholerae using the Dictyostelium host model system. Proc. Natl. Acad. Sci. U.S.A. 103:1528-1533

Quinones, B., Dulla, G., and Lindow, S. E. 2005. Quorum sensing regulates exopolysaccharide production, motility, and virulence in Pseudomonas syringae. Mol. Plant-Microbe Interact. 18:682-693.

Quinones, B., Pujol, C. J., and Lindow, S. E. 2004. Regulation of AHL production and its contribution to epiphytic fitness in Pseudomonas syringae. Mol. Plant-Microbe Interact. 17:521-531.

Raaijmakers, J. M., de Bruijn, I., and de Kock, M. J. D. 2006. Cyclic lipopeptide production by plant-associated Pseudomonas spp.: Diversity, activity, biosynthesis, and regulation. Mol. Plant-Microbe Interact. 19:699-710.

Robert-Seilaniantz, A., Shan, L., Zhou, J.-M., and Tang, X. 2006. The Pseudomonas syringae pv. tomato DC3000 Type III effector HopF2 has a putative myristolation site required for its avirulence and virulence functions. Mol. Plant-Microbe Interact. 19:130-138.

Rohmer, L., Guttman, D. S., and Dangl, J. L. 2004. Diverse evolutionary mechanisms shape the type III effector virulence factor repertoire in the plant pathogen Pseudomonas syringae. Genetics 167:1341-1360.

Roine, E., Raineri, D. M., Romantschuk, M., Wilson, M., and Nunn, D. N. 1998. Characterization of type IV pilus genes in Pseudomonas syringae pv. tomato DC3000. Mol. Plant-Microbe Interact. 11:1048-1056.

Rosebrock, T. R., Zeng, L., Brady, J. J., Abramovitch, R. B., Xiao, F., and Martin, G. B. 2007. A bacterial E3 ubiquitin ligase targets a host protein kinase to disrupt plant immunity. Nature 448:370-374.

Sarkar, S. F., and Guttman, D. S. 2004. Evolution of the core genome of 
Pseudomonas syringae, a highly clonal, endemic plant pathogen. Appl. Environ. Microbiol. 70:1999-2012.

Sawada, H., Kanaya, S., Tsuda, M., Suzuki, F., Azegami, K., and Saitou, N., 2002. A phylogenomic study of the OCTase genes in Pseudomonas syringae pathovars: The horizontal transfer of the $\operatorname{argK}$-tox cluster and the evolutionary history of OCTase genes on their genomes. J. Mol. Evol. 54:437-457.

Schell, M. A., Ulrich, R. L., Ribot, W. J., Brueggemann, E. E., Hines, H. B., Chen, D., Lipscomb, L., Kim, H. S., Mrazek, J., Nierman, W. C., and Deshazer, D. 2007. Type VI secretion is a major virulence determinant in Burkholderia mallei. Mol. Microbiol. 64:1466-1485.

Sonnhammer, E. L., and Durbin, R. 1994. A workbench for large-scale sequence homology analysis. Comput. Appl. Biosci. 10:301-307.

Spiers, A. J., Bohannon, J., Gehrig, S. M., and Rainey, P. B. 2003. Biofilm formation at the air-liquid interface by the Pseudomonas fluorescens SBW25 wrinkly spreader requires an acetylated form of cellulose. Mol. Microbiol. 50:15-27.

Sundin, G. W., and Murillo, J. 1999. Functional analysis of the Pseudomonas syringae rulAB determinant in tolerance to ultraviolet B 290-320 $\mathrm{nm}$ radiation and distribution of rulAB among $P$-syringae pathovars. Environ. Microbiol. 1:75-87.

Tobes, R., and Pareja, E. 2005. Repetitive extragenic palindromic sequences in the Pseudomonas syringae pv. tomato DC3000 genome: Extragenic signals for genome reannotation. Res. Microbiol. 156:424-433.

Tobes, R., and Pareja, E. 2006. Bacterial repetitive extragenic palindromic sequences are DNA targets for Insertion Sequence elements. BMC Genomics 7:62. Published online.

Toth, I. K., Pritchard, L., and Birch, P. R. J. 2006. Comparative genomics reveals what makes an enterobacterial plant pathogen. Ann. Rev. Phytopath. 44:305-336.

Ude, S., Arnold, D. L., Moon, C. D., Timms-Wilson, T., and Spiers, A. J. 2006. Biofilm formation and cellulose expression among diverse environmental Pseudomonas isolates. Environ. Microbiol. 8:1997-2011.

Underwood, W., Melotto, M., and He, S. Y. 2007. Role of plant stomata in bacterial invasion. Cell. Microbiol. 9:1621-1629.

Vencato, M., Tian, F., Alfano, J. R., Buell, C. R., Cartinhour, S., DeClerck, G. A., Guttman, D. S., Stavrinides, J., Joardar, V., Lindeberg, M., Bronstein, P. A., Mansfield, J. W., Myers, C. R., Collmer, A., and Schneider, D. J. 2006. Bioinformatics-enabled identification of the HrpL regulon and type III secretion system effector proteins of Pseudomonas syringae pv. phaseolicola 1448A. Mol. Plant-Microbe Interact. 19:1193-1206.

Ventre, I., Goodman, A. L., Vallet-Gely, I., Vasseur, P., Soscia, C., Molin, S., Bleves, S., Lazdunski, A., Lory, S., and Filloux, A. 2006. Multiple sensors control reciprocal expression of Pseudomonas aeruginosa regulatory RNA and virulence genes. Proc. Natl. Acad. Sci. U.S.A. 103:171-176.

Vernikos, G. S. and Parkhill, J. 2006. Interpolated variable order motifs for identification of horizontally acquired DNA: Revisiting the Salmonella pathogenicity islands. Bioinformatics 22:2196-2203.

Vieira, J., Mendes, M. V., Albuquerque, P., Morades-Ferreira, P., and Tavares, F. 2007. A novel approach for the identification of bacterial taxa-specific molecular markers. Lett. App. Microbiol. 44:506-512.

Vigneux, F., Zumbihl, R., Jubelin, G., Ribeiro, C., Poncet, J., Baghdiguian, S., Givaudan, A., and Brehelin, M. 2007. The $x a x A B$ genes encoding a new apoptotic toxin from the insect pathogen Xenorhabdus nematophila are present in plant and human pathogens. J. Biol. Chem. 282:9571-9580.

Vodovar, N., Vallenet, D., Cruveiller, S., Rouy, Z., Barbe, V., Acosta, C., Cattolico, L., Jubin, C., Lajus, A., Segurens, B., Vacherie, B., Wincker, P., Weissenbach, J., Lemaitre, B., Medigue, C., and Boccard, F. 2006. Complete genome sequence of the entomopathogenic and metabolically versatile soil bacterium Pseudomonas entomophila. Nat. Biotechnol. 24:673-679.

Waterfield, N. R., Bowen, D. J., Fetherston, J. D., Perry, R. D., and ffrench-Constant, R. H. 2001. The tc genes of Photorhabdus: A growing family. Trends Microbiol. 9:185-191.

Wei, C. F., Kvitko, B. H., Shimizu, R., Crabill, E., Alfano, J. R., Lin, N. C., Martin, G. B., Huang, H. C., and Collmer, A. 2007. A Pseudomonas syringae pv. tomato DC3000 mutant lacking the type III effector HopQ1-1 is able to cause disease in the model plant Nicotiana benthamiana. Plant J. 51:32-46.

Welch, R. A., Burland, V., Plunkett, G., III, Redford, P., Roesch, P., Rasko, D., Buckles, E. L., Liou, S. R., Boutin, A., Hackett, J., Stroud, D., Mayhew, G. F., Rose, D. J., Zhou, S., Schwartz, D. C., Perna, N. T., Mobley, H. L. T., Donnenberg, M. S., and Blattner, F. R. 2002. Extensive mosaic structure revealed by the complete genome sequence of uropathogenic Escherichia coli. Proc. Natl. Acad. Sci. U.S.A. 99:17020-17024.

Wood, J. M. 1999. Osmosensing by bacteria: signals and membrane-based sensors. Microbiol. Mol. Biol. Rev. 63:230-262.

Xing, W., Zou, Y., Liu, Q., Liu, J., Luo, X., Huang, Q., Chen, S., Zhu, L., Bi, R., Hao, Q., Wu, J.-W., Zhou, J.-M., and Chai, J. 2007. The structural basis for activation of plant immunity by bacterial effector protein AvrPto. Nature 449:243-247.

Yu, J., Penaloza-Vazquez, A., Chakrabarty, A. M., and Bender, C. L. 1999. Involvement of the exopolysaccharide alginate in the virulence and epiphytic fitness of Pseudomonas syringae pv. syringae. Mol. Microbiol. 33:712-720.

Zhao, Y., Thilmony, R., Bender, C. L., Schaller, A., He, S. Y., and Howe, G. A. 2003. Virulence systems of Pseudomonas syringae pv. tomato promote bacterial speck disease in tomato by targeting the jasmonate signaling pathway. Plant J. 36:485-99.

\section{AUTHOR-RECOMMENDED INTERNET RESOURCE}

Pseudomonas-Plant Interaction website: www.pseudomonas-syringae.org 